\title{
On local scouring downstream small water structures (\#46700)
}

First revision

\section{Guidance from your Editor}

Please submit by $\mathbf{9}$ Oct $\mathbf{2 0 2 0}$ for the benefit of the authors .

\section{Structure and Criteria}

Please read the 'Structure and Criteria' page for general guidance.

\section{Author notes}

Have you read the author notes on the guidance page?

\section{Raw data check}

HE Review the raw data.

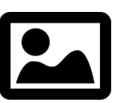

\section{Image check}

Check that figures and images have not been inappropriately manipulated.

Privacy reminder: If uploading an annotated PDF, remove identifiable information to remain anonymous.

\section{Files}

Download and review all files from the materials page.
1 Tracked changes manuscript(s)

1 Rebuttal letter(s)

12 Figure file(s)

7 Table file(s)

1 Raw data file(s) 


\section{Structure your review}

The review form is divided into 5 sections. Please consider these when composing your review:

\section{BASIC REPORTING}

2. EXPERIMENTAL DESIGN

3. VALIDITY OF THE FINDINGS

4. General comments

5. Confidential notes to the editor

You can also annotate this PDF and upload it as part of your review

When ready submit online.

\section{Editorial Criteria}

Use these criteria points to structure your review. The full detailed editorial criteria is on your guidance page.

\section{BASIC REPORTING}

Clear, unambiguous, professional English language used throughout.

Intro \& background to show context. Literature well referenced $\&$ relevant.

Structure conforms to Peer] standards, discipline norm, or improved for clarity.

Figures are relevant, high quality, well labelled \& described.

Raw data supplied (see Peer] policy).

\section{EXPERIMENTAL DESIGN}

Original primary research within Scope of the journal.

Research question well defined, relevant \& meaningful. It is stated how the research fills an identified knowledge gap.

Rigorous investigation performed to a high technical \& ethical standard.

Methods described with sufficient detail \& information to replicate.

\section{VALIDITY OF THE FINDINGS}

Impact and novelty not assessed.

Negative/inconclusive results accepted. Meaningful replication encouraged where rationale $\&$ benefit to literature is clearly stated.

All underlying data have been provided; they are robust, statistically sound, $\&$ controlled.
Speculation is welcome, but should be identified as such.

Conclusions are well stated, linked to original research question $\&$ limited to supporting results. 


\section{Standout \\ reviewing tips}

The best reviewers use these techniques

Tip

\section{Support criticisms with evidence from the text or from other sources}

\section{Give specific suggestions on how to improve the manuscript}

\section{Comment on language and grammar issues}

\author{
Please provide constructive \\ criticism, and avoid personal \\ opinions
}

\section{Example}

Smith et al (J of Methodology, 2005, V3, pp 123) have shown that the analysis you use in Lines 241-250 is not the most appropriate for this situation. Please explain why you used this method.

Your introduction needs more detail. I suggest that you improve the description at lines 57- 86 to provide more justification for your study (specifically, you should expand upon the knowledge gap being filled).

The English language should be improved to ensure that an international audience can clearly understand your text. Some examples where the language could be improved include lines 23, 77, 121, 128 - the current phrasing makes comprehension difficult.

1. Your most important issue

2. The next most important item

3....

4. The least important points

I thank you for providing the raw data, however your supplemental files need more descriptive metadata identifiers to be useful to future readers. Although your results are compelling, the data analysis should be improved in the following ways: $A A, B B, C C$

I commend the authors for their extensive data set, compiled over many years of detailed fieldwork. In addition, the manuscript is clearly written in professional, unambiguous language. If there is a weakness, it is in the statistical analysis (as I have noted above) which should be improved upon before Acceptance.
Comment on strengths (as well as weaknesses) of the manuscript 


\title{
On local scouring downstream small water structures
}

\author{
Marta Kiraga ${ }^{\text {Corresp., } 1}$, Zbigniew Popek ${ }^{2}$ \\ 1 Department of Hydrotechnics and Technology, Institute of Civil Engineering, Warsaw University of Life Sciences WULS-SGGW, Warsaw, Poland \\ 2 \\ 2 Department of Water Engineering and Applied Geology, Institute of Environmental Engineering, Warsaw University of Life Sciences WULS-SGGW, \\ Warsaw, Poland \\ Corresponding Author: Marta Kiraga \\ Email address: marta_kiraga@sggw.edu.pl
}

Background. In order to regulate the water flow hydraulic structures such as weirs or checks, frequently equipped with gates, are used. Water can flow below or over the gate or, simultaneously, over and below the gate. Both diversifications of hydraulic gradient, being an effect of damming up a river by the structure and shear stresses at the bed, which exceeds the critical shear stress value, invoke the local scouring downstream the structure. This phenomenon has been studied in laboratory and field conditions for many years, however Researchers do not agree on the parameters that affect the size of the local scour and the intensity of its formation. There are no universal methods for estimating its magnitude However, solutions are sought in the form of calculation formulas typical for the method of flow through the structure, taking into account the parameters that characterize a given structure. These formulas are based on factors that affect the size of the local scours, that is, their dimensions and location. Examples of such formulas are those contained in this article: Franke (1960), Straube (1963), Tarajmovič (1966), Rossinski \& Kuzmin (1969) equations. The need to study this phenomenon results from the prevalence of hydrotechnical structures equipped with gates (from small gated checks to large weirs) and from potential damage that may be associated with excessive development of local erosion downstream, including washing of foundations and, consequently, loss of stability of the structure.

Methods. This study verifies empirical formulas applied to estimate the geometry parameters of a scour hole on a laboratory model of a structure where water is conducted downstream the gate with bottom reinforcements of various roughness. A specially designed remote-controlled measuring device, equipped with laser scanner, was applied to determine the shape of the sandy bottom. Then the formula optimization is conducted, using Monte Carlo sampling method, followed by verification of field conditions.

Results. The suitability of a specially designed device, equipped with laser scanner for measuring the bottom shape in laboratory conditions was demonstrated. Simple formula describing local scour geometry in laboratory conditions was derived basing on the Straube formula. The optimized formula was verified in field conditions giving very good comparative results. Therefore, it can be applied in engineering and designing practices. 


\section{On local scouring downstream small water structures}

2

3 Marta Justyna Kiraga ${ }^{1}$, Zbigniew Popek ${ }^{2}$

4

$5 \quad{ }^{1}$ Department of Hydrotechnics and Technology, Institute of Civil Engineering, Warsaw

6 University of Life Sciences WULS - SGGW, Warsaw, Poland

$7 \quad 2$ Department of Water Engineering and Applied Geology, Institute of Environmental

8 Engineering, Warsaw University of Life Sciences WULS - SGGW, Poland 9

10 Corresponding Author:

11 Marta Justyna Kiraga

12159 Nowoursynowska Str, Warsaw, 02-776, Warszawa

13 Email address: marta_kiraga@sggw.edu.pl 


\section{Abstract}

42 Background. In order to regulate the water flow hydraulic structures such as weirs or checks, 43 frequently equipped with gates, are used. Water can flow below or over the gate or,

44 simultaneously, over and below the gate. Both diversifications of hydraulic gradient, being an 45 effect of damming up a river by the structure and shear stresses at the bed, which exceeds the 46 critical shear stress value, invoke the local scouring downstream the structure. This phenomenon has been studied in laboratory and field conditions for many years, however Researchers do not agree on the parameters that affect the size of the local scour and the intensity of its formation. There are no universal methods for estimating its magnitude However, solutions are sought in the form of calculation formulas typical for the method of flow through the structure, taking into account the parameters that characterize a given structure. These formulas are based on factors that affect the size of the local scours, that is, their dimensions and location. Examples of such formulas are those contained in this article: Franke (1960), Straube (1963), Tarajmovič (1966), Rossinski \& Kuzmin (1969) equations. The need to study this phenomenon results from the prevalence of hydrotechnical structures equipped with gates (from small gated checks to large weirs) and from potential damage that may be associated with excessive development of local erosion downstream, including washing of foundations and, consequently, loss of stability of the structure.

Methods. This study verifies empirical formulas applied to estimate the geometry parameters of a scour hole on a laboratory model of a structure where water is conducted downstream the gate with bottom reinforcements of various roughness. A specially designed remote-controlled measuring device, equipped with laser scanner, was applied to determine the shape of the sandy bottom. Then the formula optimization is conducted, using Monte Carlo sampling method, followed by verification of field conditions.

\section{Results. The suitability of a specially designed device, equipped with laser scanner for} measuring the bottom shape in laboratory conditions was demonstrated. Simple formula describing local scour geometry in laboratory conditions was derived basing on the Straube formula. The optimized formula was verified in field conditions giving very good comparative results. Therefore, it can be applied in engineering and designing practices.

\section{Introduction}

The article addresses the subject of hydraulic structures, understood as structures for water management, shaping water resources and water use (Chen 2015). The analyzed case is a damming structure i.e. a structure enabling permanent or periodical maintenance of a water surface level elevation above the adjacent land or body of water. There is a strong link between water and environment, as well as between water and development, both with opposite aims. While the willingness to develop and expand the hydrotechnical infrastructure is a drive for economic development and thus for urbanization to flourish, the environmental aspects direct the designer rather towards sustainable solutions (Koskinen, Leino \& Riipinen 2008; Jordaan 2009; Rasekh, Afshar \& Afshar 2010) and, as engineering practice demonstrated, to reject a project at 
81 an early stage. It should be denoted that a failure of a hydrotechnical structure does not only

82

83

84

85

86

87

88

89

90

91

92

93

94

95

96

97

98

99

100

101

102

103

104

105

106

107

108

109

110

111

112

113

114

115

116

117

118

119

120

concern dams of significant sizes but also small hydraulic structures (usually not taken into account by ecologists) which are a potential source of disaster, affecting the life and economy of a given region (Hossain 1992; Lopardo \& Seoane 2004).

There are many criteria in the design of hydraulic structures that must be optimized at the same time. Construction, operating and maintenance costs, construction reliability, environmental impact, social disruption and potential loss of life can be identified as one of the most noticeable of a large number of criteria (Rasekh, Afshar \& Afshar 2010). Therefore, a comprehensive research on the environmental risk of hydrotechnical structures failure is necessary. One aspect of this type of research is a proper recognition of hydraulic and morphodynamic processes that accompany the construction of water structures using physical and mathematical models (Lopardo \& Seoane 2004; Syvitski et al. 2010).

Damming up rivers by implementation of a hydraulic structure unavoidably influences the stream course and valley morphology. Upstream the structure, due to the water surface level increment the water can flood the adjacent valley and the reservoir may form. Due to the crosssection enhancement and, therefore, stream velocity reduction, sediment sedimentation and accumulation may occur when the weight of the ground particles will outweigh the transport capacity of the water stream (Graf 1989). Simultaneously, erosion can intensify downstream the structure, especially in the case of very low water surface level and the stream velocity rapid enhancement. The debris-free stream leaving the dammed structure, with additional kinetic energy and increased turbulence, has a high eroding capacity (Szydłowski \& Zima 2006; Pagliara \& Kurdinstani 2013; Zobeyer et al. 2010; Lee \& Hong 2019). The effect of intensified erosion, which takes place downstream the structure, is mainly local scouring and gradual lowering of the bottom on an increasingly longer section of the river. The increased erosion of a riverbed is unfavorable and undesirable not only due to slow degradation of the riverbed, but also because of occurrence of rapid morphodynamic processes. It is commonly assumed that the most intensive transformation of riverbeds takes place during catastrophic flooding when basic hydrodynamic parameters of the stream increase many times. Excessive development of a scour hole directly behind the structure, such as weir or sluice, poses a threat to its safety as it may lead to washing away the foundation, embankments damages and loss of stability (Bajkowski, Siwicki, Urbański 2002). Removing and repairing these undesirable effects is troublesome and expensive. Therefore, technical solutions are needed to reduce scour hole dimensions.

Due to a focus on ecological changes in aquatic environment and the adjacent area in recent decades, it is worth considering what environmental benefits of local scouring can be. In order to specify them, it is necessary to identify this phenomenon more precisely i.e. to know the causes of its occurrence, its characteristics and the process over time (Siwicki, Urbański 2004).

The specific character of the flow within a scour area is a certain diversity of conditions in comparison with a river in its natural course. Stream velocity and associated physical forces constitute the most important environmental factor affecting organisms living in watercourses (Cullen 1991; Smith, Goodwin \& Nestler 2014).

Peer) reviewing PDF | (2020:03:46700:1:1:NEW 3 Sep 2020) 
A significant reduction of stream velocity in a bottom local scour area leads to a specific flow region formation named the wall-adjacent boundary layer. This layer can serve as a shelter for organisms from turbulence and high water velocities. In well-developed scour holes, the nearzero stream velocity in the wall-adjacent boundary layer can form local areas of still water (Lupandin 2005; Liao \& Cotel 2013; Hockley et al. 2013). The adaptation of fish to living in still and flowing water has been extensively studied and it was found that one of the most important environmental factors is the dissolved oxygen content of the water. The higher the stream velocity and turbulence intensity, the more oxygenated the water is. Therefore, the water after passing through the structure is aerated as evidenced by the measured increases in speed and turbulence of the stream in the position downstream compared to the upper structure (Kobus \& Koschitzky 2014).

As a result of the process of sorting and armoring, i.e. washing out finer particles and leaving thicker fractions at the bottom, the material is sorted on the scour hole bottom surface and a layer made of thicker fractions is formed. These are the factors that determine the structure of the velocity field at the bottom. This type of scouring process creates quite favourable environmental conditions for many species of fish, i.e. a well aerated stream, thicker material on the bottom and a smooth type of stream in the wall-adjacent boundary layer area (Siwicki, Urbański 2004; Ochman \& Kaszubkiewicz 2004; Hauer et al. 2018).

Local scouring in the aquatic environment may be particularly desirable during the season of low dischagres. It can then serve as a reservoir in which particular species that require a certain water depth, can survive. Lowering of the river bed may also be beneficial in the construction of a fish pass. The inlet and outlet of fishponds must be submerged deep enough under the water surface level, and this could be difficult in the structure stand downstream, where the depth of the stream is normally lower than in upstream stand area (Siwicki, Urbański 2004). At the design stage, it is important to develop a reliable forecast of a size, shape and position of the local scour, both in dams and small hydraulic structures, such as gated checks, weirs or sluices.

Gated checks are small river training structures, applied for limiting channel incision, bed stabilization, reducing flow velocity and raising upstream water level. These structures are often used in channels where the adjustment of water level is required more frequently or where higher cost compared to stop-logs, are justified (e.g. saving of labour). Gated checks are usually equipped with hand-operated slide gates of various types, from simple wooden shutters to handwheel operated adjustable orifice type gates (Kraatz \& Mahajan 1975).

Although many studies on local scouring downstream hydraulic structures can be found in the literature in the recent years (for example Sun, Wang \& Wang 2012; Pagliara et al. 2016; Khaple et al. 2017; Al-Husseini, Al-Madhhachi \& Naser 2019; Singh, Devi \& Kumar 2020; Li el al. 2020; Taha, El-Feky \& Fathy 2020; Wang et al. 2020; Yan, Rennie, Mohammadian 2020), among them only a few focus on small hydraulic structures (Lopardo \& Seoane 2004; Kiraga \& Popek 2016; Odgaard 2017; Al-Suhaili, Abbood \& Samir Saleh 2017; Kiraga \& Popek 2018). Especially gated checks are a rare object of research, which, given quite high prevalence of this type of structures, determines the appropriateness of the undertaken subject. 
In recent years, the role of small retention of valley areas was emphasized (Boix et al. 2012; Mioduszewski 2014). A significant role in maintaining and increasing retention is played by small water structures (Lopardo \& Seoane 2004) whichare less popular in the research subject matter than bridges or larger weirs with controlled closures.

It should also be noted that hydraulic instrumentation has advanced significantly, so fundamental flow parameters or river bed shape can be measured with greater precision. For instance, the PIV imaging anemometry system can be used to describe the distribution of velocity fields in the area of water structure and the description of a bottom shape can be perform using an echo sounder, e.g. fixed on a boat, or by laser scanning technique (Hager \& Boes 2014; Killinger 2014).

Most of the research samples in order to identify the factors influencing the amount of local scouring to the greatest extent below water structures were carried out in laboratory conditions. The following factors that influence a scour hole shape and location are: -- related to the flume geometry (width, depth, bed inclination); -- related to the type and geometry of the structure (type of structure, reinforcement construction, dimensions of upstream and downstream part of the structure elements);

-- characterizing water flow conditions (flow rate, average speed, hydraulic gradient, bed shear stress, flow resistance),

-- water properties (density, viscosity),

-- characterizing the flume material (grain size, grain distribution, density, porosity, roughness), -- characterizing the conditions of sediment transport (critical velocity, critical shear stress, sediment transport intensity), -- time (Graf 1989; Breusers \& Raudkivi 1991; Kiraga \& Popek 2019).

In spite of many experimental works carried out under various constructional conditions and high variability of hydraulic conditions, the universal principles of calculating the local scour dimensions and transferring it to field conditions are still unknown. Solutions are sought, involving different coefficients, which characterize a given construction, based on identified factors that influence scour size and position (Franke 1960; Straube 1963; Tarajmovič 1966; Rossinski \& Kuzmin 1969). The formation and expansion of local scouring that results from time-varying, two-phase movement of water and sediment is one of the most undiscovered processes in hydrotechnical engineering (Graf 1998; Nouri Imamzadehei et al. 2016). Despite numerous studies carried out since the first decades of last century (for example Lacey 1946; Ahmad 1953; Breusers \& Raudkivi 1991; Lenzi, Marion \& Comiti 2003; Ben Meftah \& Mossa 2006; Kiraga \& Popek 2016; Pagliara et al. 2016; Kiraga \& Popek 2018; Al-Husseini, AlMadhhachi \& Naser 2019), there is no sufficient and unquestionable basis for the mathematical description of the process of local erosion, and thus for a development of forecasts of scour holes that will occur during the design of structures. Also, it is not always possible to predict fully reliable estimation based on the results of laboratory tests, because in laboratories the researchers are usually unable to lead to the occurrence of the so-called final scour, i.e. to a state in which the extension of the duration of the experiment does not cause changes in the dimensions and 
201 location of sandy bottom and banks (Chabert \& Engeldinger 1956; Barbhuiya \& Dey 2004).

202 Moreover, designers find it difficult to choose those that give reliable results. Due to the

203 diversity of applied constructions of structures and the variability of hydraulic conditions, it is

204 difficult to generalize the derived formulas (Graf, 1998; Barbhuiya \& Dey 2004; Ben Meftah \&

205 Mossa 2006).

206 The absence of a forecast of the effects of local erosion makes it impossible to rationally assess

207 the degree of safety and certainty of the use of a hydraulic structure, since the scour poses a

208 similar threat to the structure, such as insufficient structure capacity, too low structural stability

209 coefficient, ground strength exceeding, etc.

210 The complexity of a local scouring process means that only fragments of the problem are

211 usually examined with limited objectives, such as:

212 -- explanation of the influence of factors, e.g. the construction of downstream part of the

213 structure, length and roughness of the reinforcements, etc. (Rossinski \& Kuzmin 1969; Al-

214 Mohammed, Jassin \& Abbas 2019);

215 -- highlighting the effectiveness of various design solutions to prevent excessive erosion

216 (Epely-Chauvin, De Cesare \& Schwindt 2015; Taha, El-Feky \& Fathy 2020);

217 -- formulation of dependencies, formulas, etc. to determine scour forecasting for assumed 218 geometrical, hydraulic and ground conditions (Gaudio \& Marion 2003; Kiraga \& Popek 2019).

219 Additionally, the results of tests carried out in a laboratory are difficult to translate directly into 220 field conditions due to the scale effect (Farhoudi \& Smith, 1985), whereas during field tests 221 problems result mainly from the lack of knowledge of the initial conditions, i.e. the shape of the 222 bottom before disturbing the existing dynamic balance in the channel (Lenzi, Marion \& Comiti, 223 2003; Pagliara et al., 2016).

224 Researchers agree that regardless of a construction of ahydraulic structure, the depth of the 225 scour hole is influenced by length, roughness and height position of the fortifications 226 downstream. (Rossinski \& Kuzmin 1969; Urbański 2008; Taha, El-Feky \& Fathy 2020). 227 Difficulties in explaining and presenting the influence of factors on the process of scouring and 228 the lack of perspectives for establishing universal relations between the complicated flow system 229 and the sediment transport, lead to use simple, in fact intuitive, relationships that allow to 230 determine the depth of local scour.

231 The estimation of the maximal scour hole depth and the channel reach infested by extensive 232 erosion allows for a proper design of the downstream of hydraulic structure, ensuring safety and 233 stability, as well as reducing the construction and subsequent operation cost. Therefore, the 234 estimation of the geometry of forecasted scour should be an integral part of the design stage of 235 hydrotechnical structures (Brandimarte, Paron \& Di Baldasarre, 2012; Prendergast \& Gavin, 236 2014).

237 Difficulties of local scouring investigations result primarily from the multitude of factors 238 influencing its shape and dimensions. The following factors can be mentioned among them 239 (Franke 1960; Straube 1963; Tarajmovič 1966; Rossinski \& Kuzmin 1969): 
240

241

242

243

244

245

246

247

248

249

250

251

252

253

254

255

256

257

258

259

260

261

262

263

264

265

266

267

268

269

270

271

272

273

274

275

276

277

278

279

--relation to the flume or channel geometry (e.g. the Shalash and Franke, Müller, Tajarmovič formula);

--relation to the type and geometry of the structure (e.g. the Rossinski formula);

--relation to water flow conditions, such as flow rate, average speed or flow resistance);

--water physical properties;

--relation to bed material (e.g. the Straube method).

This paper comprises the identification, verification and validation of chosen empirical formulas: Shalash \& Franke, Straube, Müller and Tarajmovič serving to estimate the scour dimensions in local scour process forming due to damming up the flume by the gate, equipped with downstream stage embankment. For formula optimization the Monte Carlo sampling method was applied. Laboratory research was performed as a first part of the studies, then the formula best describing flume experiment was verified in field conditions.

\section{Materials \& Methods}

Research based on laboratory studies was performed in a 11-m long hydraulic flume with 0.58 $\mathrm{m}$ width. No bed inclination downstream was introduced, however it should be noted that lowland rivers that formed in alluvial depositions usually have gradients of $0.5-3 \%$. If such a slope were to be reproduced in the present laboratory conditions, the difference in elevation of the bottom below the water structure would be $1 \mathrm{~mm}$ to a maximum of $1 \mathrm{~cm}$.

Data were collected as previously described in the publication "Bed shear stress influence on local scour geometry properties in various flume development conditions" in Water by Marta Kiraga and Zbigniew Popek (2019). Specifically, the research assumed bed shape measurements during local scouring formation, both using pin gauge, laser scanning of the surface and water surface level examination in presumed hydraulic conditions. However, the examined flume development differs from the mentioned publication in Water. Namely, two gated check models assumed slide gate introduction, which was constantly raised to $5 \mathrm{~cm}$ of height to ensure invariable flow area of $0.029 \mathrm{~m}^{2}$ (Figure $1 \mathrm{a}, \mathrm{b}$ ). In the vicinity of the damming structure, the bottom was solid on the length of $L_{1}=0.30 \mathrm{~m}$ upstream the gate and $L_{2}=0.80 \mathrm{~m}$ downstream, designed to imitate bed reinforcement typical for weirs or other river training structures, often made of concrete or rip rap. The reinforcement downstream the check was made of plain slab working as a reinforcement within the model I of flume development (Figure 2 a, 3 a) (4), whereas model II assumed stone riprap reinforcement made of rocks (8) whose medium height was $1.5 \mathrm{~cm}$ (Figure $2 \mathrm{~b}, 3 \mathrm{~b}$ ). A scour hole formed inside a sandy part downstream the check with a length $L_{3}$ of $2.20 \mathrm{~m}$ (2). The applied constructional solution of the model assumed representation of water flow under a partially open valve of the gated check with lowered reinforced bottom below with variable roughness where sediment transport takes place through the gate - not held by any weir. According to Kraatz \& Mahajan (1975) the length of the reinforcement downstream the gated check should be ca. 1.5 times longer than the width of the gate - and the model applied within present experiment ensure the elements' dimensions close to this ratio.

Peer] reviewing PDF | (2020:03:46700:1:1:NEW 3 Sep 2020) 
280

281

282

283

284

285

286

287

288

289

290

291

292

293

294

295

296

297

298

299

300

301

302

303

304

305

306

307

308

309

310

311

312

313

314

315

316

317

318

319
Bottom shape was investigated at all flume lengths. After each measurement series, the sand in the flume was dried for ca. 13 hours - the outflowing water was removed by using drainage pipe ( 5 in Figure $2 \mathrm{a}$ and $\mathrm{b}$ ). The measurement schedule was similar as previously described in "Bed shear stress influence on local scour geometry properties in various flume development conditions" in Water by Marta Kiraga and Zbigniew Popek (2019). Namely, pin water gauges were used in order to measure water surface elevation at the intake part and along the flume in the central axis (1). The water surface level was regulated with an outlet gate (6). Before introducing water into the flume and after draining the sand the final level of sandy bottom was measured with a laser scanner (7) and with a moving disc probe (1) as a supportive device in presumed time steps $(0.5-2 \mathrm{~h})$.

Before starting each measurement series and introducing water stream into the flume, the sandy bed was uniformly adjusted to a constant level and compacted with load of $2.5 \mathrm{~kg}$ dropped to the bed surface with an energy of about $5 \mathrm{~J}$. Then, the position of the bottom was measured with a disc probe with presumed mesh $5 \times 7 \mathrm{~cm}$ to $20 \times 10 \mathrm{~cm}$ both upstream and downstream the hydraulic structure.

As described in "Bed shear stress influence on local scour geometry properties in various flume development conditions" in Water by Marta Kiraga and Zbigniew Popek (2019) flume side walls were made of glass with a roughness coefficient $n_{w}=0.010 \mathrm{~s} \cdot \mathrm{m}^{-1 / 3}$. The soil used during the study was uniform coarse sand with medium diameter $d_{50}=0.91$ and $d_{95}=1.2 \mathrm{~mm}$ and roughness coefficient $n_{b}=0.028 \mathrm{~s} \cdot \mathrm{m}^{-1 / 3}$. Experiments were performed in the scope of steady water flow discharge within the following range $Q_{w}=0.010-0.045 \mathrm{~m}^{3} \cdot \mathrm{s}$, water depth downstream the structure $h=0.05-0.26 \mathrm{~m}$ and Froude number $\mathrm{Fr}<1.29$ measurement series were performed, each lasting 8 hours ( 9 measurement series on model I and 20 on model II) (Table 1 and 2).

No sediment feeding system was adopted. Bedload transport conditions were assured by specific set of hydraulic conditions that invokes particle movement from upstream towards downstream. Therefore, the experiment was carried out in 'live-bed' conditions, where soil leaving the scour hole is substituted by approaching load from the upstream. It is worthy to notice that for typical lowland rivers both bedload load and suspended load are present in various relations. For example, the suspended load constitutes $60-70 \%$ of the whole sediment load transported by Vistula River in Poland and 50-90\% of that is transported by its tributaries (Lajczak 1996), although only bedload was investigated in this study.

A group of experiments carried out in a hydraulic laboratory, the results of which were published, among others, in Water or IEEE Access journals (Kiraga and Popek 2016; Kiraga and Popek 2019; Kiraga and Miszkowska 2020), concerned the phenomenon of formation of local scouring as a result of not only varied roughness of the materials building the bed, but also the restriction of the flow field by inserting a model of damming structures into the flume. Namely, due to the flow resistance increment along the whole flume resulting from varied roughness of solid and sandy bottom, the hydraulic gradient increases causing the intensification of shear stress at the bottom. After exceeding the critical shear stress, the motion of sediment grains

Peer] reviewing PDF | (2020:03:46700:1:1:NEW 3 Sep 2020) 
320

321

322

323

324

325

326

327

328

329

330

331

332

333

334

335

336

337

338

339

340

341

342

343

344

345

346

347

348

349

350

351

352

353

354

355

356

357

358

starts, followed by gradual scouring of the bed. Maximal scour depth $z_{\max }$, scour length $L_{s}$ and the distance between the deepest point of the hole and the end of reinforcement $L_{e}$ were examined (Figure 4) during each measurement.

In order to investigate the final scour shape both a device equipped with laser scanner and a disc probe were applied as supportive devices. Data were collected as previously described in "Bed shear stress influence on local scour geometry properties in various flume development conditions" in Water by Marta Kiraga and Zbigniew Popek (2019). Prototype A1 of the device was engineered in 2016 by Marta Kiraga and Matvey Razumnik within the university grant for young researchers "The influence of small hydraulic structures on sediment transport conditions" (Kiraga et al. 2018).

Prototype A1 (Figure 5) is equipped with a laser rangefinder and automatic movement system embedded on guides along the flume, scanning the bottom area with a demanded grid (every $1 \mathrm{~mm}$ in case of present experiments). Grid density alteration possibility gives a far greater accuracy of measurement than the disc probe. The use of the device ensures data transmission directly in digital form, so that the coordinates can be easily processed to obtain the desired scour hole geometrical parameters.

Laser scanning, also known as LiDAR (Light Detection and Ranging) is an active tele-detection method which uses electromagnetic waves sent by the emitter. The result is point cloud with coordinates $(x, y, z)$ (Jaboyedoff et al. 2010; Killinger 2014). The measuring system (LiDAR) consists mainly of a transmitter i.e. a module generating laser light (diodes), an optical telescope focusing the returning reflected radiation and a detector converting light energy into an impulse recorded in the module that records the acquired data.

The prototype's supporting elements are made of biodegradable polyactide (PLA) and are printed on a 3D printer. Using Raspberry Pi microcomputer allows simultaneous computations and data collecting by the beam. The device is fully automated which was achieved by the application of a single board computer, dedicated software and the set of stepper motors, which results in measurements repeatability, constant accuracy on demand and fast execution of results. The obtained coordinates mesh is characterized by high resolution: $1 \mathrm{~mm}$ by $1 \mathrm{~mm}$ - therefore bottom shape is described very precisely, both in numerical form and as a graphical tracing. Numerical cloud can be easily transformed thence scour hole dimensions such as length or depth can be estimated. LiDAR technology application in scour shape and its volume in flume experiments is based on the introduction of an automatic measuring module which, placed above the bottom on a specially prepared controllable system of guides, describes its shape by creating a point cloud.

Deriving from a statement that scouring process stops when stream velocity $v$ is equal to nonscouring velocity $v_{n}$ Rossinski (Rossinski \& Kuzmin 1969) stated that water depth above the local scour can be calculated as:

$$
H=z_{\text {max }}+h=k_{1} \sqrt[1.2]{q / v_{n 1}}
$$

where $z_{\max }$ is local scour depth, [m]; $h$ is water elevation before scour formation (See Figure 4), $[\mathrm{m}] ; k_{1}$ is a dimensionless coefficient, describing intensified turbulence of the stream, [-]; $q$ is unit discharge, $\left[\mathrm{m}^{3} \cdot \mathrm{s}^{-1} \cdot \mathrm{m}^{-1}\right] ; v_{n 1}$ is non-scouring velocity for water depth of $1 \mathrm{~m}$, depending to soil properties, $\left[\mathrm{m}^{2} \cdot \mathrm{s}^{-1}\right]$ calculated as following: 


$$
v_{n 1}=\sqrt{2 g\left(\gamma_{r}-\gamma_{w}\right) / 1.75 \gamma_{w}} d_{50} \log \left(8.8 / d_{95}\right)
$$

359 in which $g$ is gravity acceleration, $g=9.81 \mathrm{~m} \cdot \mathrm{s}^{-2} ; \gamma_{r}$ and $\gamma_{w}$ are specific weights, sediment and

360 water, respectively $\left[\mathrm{N} \cdot \mathrm{m}^{-3}\right] ; d_{50}$ and $d_{95}$ are diameters that correspond to $50 \%$ and $95 \%$ of particles

361 finer than the reported particle size.

362 The $k_{1}$ value in the formula (1) is an empirical coefficient, dependent on downstream

363 development conditions. Based on practice experiences $k_{1}$ takes the value of 1.70 when the

364 reinforcement downstream the gate is not deepened and sheet piling, palisade or other vertical

365 securing element make an additional protection. Due to the stream energy enhancement in the

366 region of the gate outlet without any energy dissipating device local scouring process is intensified.

367 When transverse trench is dug downstream the reinforcement, of depth equal to the expected depth

368 of the scour; and the slope of this trench is no more than 1:4, then $k_{1}=1.05$ should be assumed

369 (Figure $6 \mathrm{a}, \mathrm{b}$ ).

370 Experimental case is referred to the conditions when coarse sandy bed is preceded by deepened 371 reinforcement downstream (Figure $6 \mathrm{c}$ ) therefore, empirical studies on $k_{1}$ parameter were needed.

372 The difficulty of explaining and presenting the impact of factors influencing local scouring 373 process in large scale hydraulic structures with the lack of perspectives for establishing relations

374 between a complicated flow system and sediment transport, forces to apply simple, intuitive

375 relations allowing for the determination of the depth of scour holes. Scour length $L_{s}$ and the

376 distance between the deepest point of the hole and the end of reinforcement $L_{e}$ where the stream

377 comes out from under the gate were determined by several authors:

378 --According to Shalash and Franke (Franke 1960):

$$
\begin{gathered}
L_{s} \text { and } L_{e}=f\left(z_{\max }\right) \\
L_{s}=11 \cdot z_{\max } \\
L_{e}=6.6 \cdot z_{\max }
\end{gathered}
$$

379

--According to Müller (Franke 1960; Straube 1963):

380

$$
\begin{gathered}
L_{s} \text { and } L_{e}=f\left(z_{\max }\right) \\
L_{s}=(9.9 \div 0.8) \cdot z_{\max } \\
L_{e}=(4.9 \div 0.5) \cdot z_{\max } \\
L_{s} \text { and } L_{e}=f\left(z_{\max }, h\right) \\
L_{s}=(6.0 \div 1.22) \cdot\left(z_{\max }+h\right) \\
L_{e}=(2.94 \div 0.59) \cdot\left(z_{\max }+h\right)
\end{gathered}
$$

382

383

--According to Straube (Straube 1963):

$$
\begin{gathered}
L_{s}=f\left(z_{\max }, q, h, d_{50}\right) \\
L_{s}=8.0 q^{0.36}\left(z_{\max }+h\right) d_{50}{ }^{-0.14} h^{-0.40} \\
L_{e}=f\left(L_{s}, h, d_{50}\right) \\
L_{e}=0.39 L_{s} d_{50}{ }^{0.12} h^{-0.12}
\end{gathered}
$$


384 385 386

387

388

389

390

391

392

393

394

395

396

397

398

399

400

401

402

403

404

405

406

407

408

409

410

411

412

413

414

415

416

417

418

The formulas (3-15) are recommended for systems in which the outflow from the gate goes directly onto unreinforced ground. For constructions equipped with reinforcement the Tajarmovič formula is recommended (Tarajmovič 1966):

$$
\begin{gathered}
L_{e}=f\left(z_{\text {max }}\right) \\
L_{e}=12.75 z_{\text {max }} 0.5
\end{gathered}
$$

Monte-Carlo integration works by comparing random samples with the function value. Straube equations can be described generally in the following forms:

$$
\begin{gathered}
L_{s}=a q^{b}\left(z_{\text {max }}+h\right) d_{50}{ }^{-c} h^{-d} \\
L_{e}=k L_{s} d_{50}{ }^{m} h^{-p}
\end{gathered}
$$

$$
\begin{aligned}
& \text { where } a, b, c, d, k, m, p \text { are function parameters which were sampled in the following ranges: } \\
& --a \in<5.0,8.0>\text {; } \\
& --b \in<0.24,0.40>\text {; } \\
& --c \in<0.10,0.20>\text {; } \\
& --d \in<0.35,0.45>\text {; } \\
& --k \in<0.30,0.60 \\
& --m \in<0.01,0.13>\text {; } \\
& --p \in<0.01,0.20>\text {. }
\end{aligned}
$$

Using a random number generator in the assumed ranges of values, 6000 combinations of parameters $a, b, c, d$ for equation (18) and 6000 combinations of parameters $k, m, p$ for equation (19) were selected. The average relative error $\delta$ for all 29 series of measurements was chosen as a criterion for evaluation of the formula described by a given combination of parameters.

The key to the accuracy and correctness of the Monte Carlo method is a random number generator. The method presents a solution to a problem as a parameter of a hypothetical population. Using a sequence of random numbers, it creates a population sample from which estimated values of the sought parameters can be obtained (Niederreiter 1992).

Next step was to verify the optimized formula on independent measurement results published in 2010 by Gaudio and Marion, performed on a flume with sandy bottom with the hydraulic structure represented by the cascade of transversal sills.

\section{Results}

Basic geometric parameters of observed scour during 29 measurement series, each characterized by unit discharge $q$ ( 9 on Model I and 20 on model II) are presented in Table 3 and 4 . Nonscouring velocity for water depth of $1 \mathrm{~m} v_{n 1}$ in presumed grain conditions was equal to $0.502 \mathrm{~m} / \mathrm{s}$. Maximal scour depth ranged from 1 to $10 \mathrm{~cm}$. The criterion for the reach infested by the scour is bed level, i.e. scour, is recognized within an area in which the depth of the bottom after 8-hour measurement series exceeds $10 \%$ of the maximum hole depth (Kiraga and Miszkowska 2020).

Within the scope of the assumed measurement schedule each measurement series were carried out with unique, within each model, variable combinations of input flow rate and water level. 
419 However, by means of variability of those combinations, the same values of unit flow rate $q$ (per

420

421

422

423

424

425

426

427

428

429

430

431

432

433

434

435

436

437

438

439

440

441

442

443

444

445

446

447

448

449

450

451

452

453

454

455

456

457

458 unit width) were obtained, which leads to a conclusion that in respect of unit flows, the repeatability of the experiments was ensured. Moreover, during the laboratory tests it was necessary to repeat some measurement series several times, e.g. due to faulty transfer of numerical data from the microcomputer used, which made it possible to check the repeatability of test results. The repetition of the tests was performed assuming the measurement series duration and under the same hydraulic conditions. Differences in the bottom formation were shown, described by means of basic geometrical parameters of the scouring in the range of $0.3-1.9 \%$ in the maximum depth of the scour hole and $2.2-4 \%$ in the range of the average depth of the scour, which indicates high repeatability of test results (Figure $7 \mathrm{a}, \mathrm{b}, \mathrm{c}$ ). Slightly more significant deviation was connected with scour parameters connected with its length: relative error ranging within $0.5-13.6 \%$ was met in total scour length and $3.0-16.6 \%$ in the case of the distance from the end of reinforcement to the deepest scour point.

The Rossinski formula (1) parameters were identified for investigated test stand due to lack of the present gate check structure construction analyses so far. Parameters identification was performed on the basis of mean relative error $\delta$ between observed scour depth and calculations results (Parameter $k_{1}$ was tested in the range 0.00 to 2.00. With $k_{1}$ equal to 1.10 , the mean relative error reached the minimum value. For the entire tested range of $k 1$ values, errors in the range of 15 - 100\% were achieved (Figure 8).

Parameters of 4,5; 7,8;10,11; 13; 15 and 17 formulas were verified for two models of gated check development. Calculated parameters of observed scour were examined in comparison with the measured ones. The criterion of comparison evaluation was mean relative error of each scour parameter estimation $\delta$ (Table 5) calculated for each group of 29 measurements.

The limitation in determining the range of a scour hole was the length of sandy part (bottom edge) $L_{3}$, which was $2.20 \mathrm{~m}$. In field studies, the length is long enough for the full scour length development - there is no sandy bed length limitation. As mentioned above, the field of the scour was considered to be an area where the bottom lowering exceeded $10 \%$ of its maximum depth in presumed time step (Figure 9). If another criterion was to be adopted, for example, a consideration of the scour hole area within the region where a bottom lowering exceeds 15 or more $\%$ of the maximum scour depth, a limiting effect of the sandy bottom downstream the structure could be avoided in some measurement series.

Investigated equations were divided into two groups:

-- simple formulas based only on maximal local scour depth $z_{\max }$ or on $z_{\max }$ and water depth $h$ before scour formation (Eq. 4, 7, 10 for total scour length estimation and Eq. 5, 8, 11, 17 for the distance between the deepest point of scour and the end of reinforcement estimation) -- formulas involving not only local scour hole depth $z_{\max }$ and the depth of water above the unwashed bottom $h$, but also grain characteristics, represented by $d_{50}$ diameter and hydraulic parameter, i.e. unit water discharge $q$ (the Straube formula - Eq. 13, 15)

Formulas that depend only on the local scour hole depth $z_{\max }$ (Shalash and Franke - Eq. 4, 5; Müller - Eq. 7,8) or on the local scour hole depth $z_{\text {max }}$ and the depth of water above the unwashed

Peer) reviewing PDF | (2020:03:46700:1:1:NEW 3 Sep 2020) 
459 bottom $h$ (Müller - Eq. 10, 11) demonstrated mean relative error of 56.9-72.8\% in the scope of 460 total scour length $L_{s}$ and $38.3-57.0 \%$ for the distance between the deepest point of scour and the 461 end of reinforcement $L_{e}$. The Tajarmovič equation (Eq. 17) indicates a 392.7\% error. Medium 462 relative error for simple formulas $(4,7,10)$ was equal to $66.5 \%$ and for formulas $(5,8,11$ and 17$)$ 463 was equal to $133.3 \%$.

464 Calculations using the formula, involving not only local scour hole depth $z_{\max }$ and the depth of

465

466

467

468

469

470

471

472

473

474

475

water above the unwashed bottom $h$, but also grain characteristics, represented by $d_{50}$ diameter and hydraulic parameter, i.e. unit water discharge $q$ (the Straube formula - Eq. 13, 15) provide the best fit to the measurement data. The relative error was $34.2 \%$ for total scour length and $32.1 \%$ for the distance between the deepest point of scour and the end of reinforcement. The Figures 10 and 11 demonstrate the results of calculations in relation to the measured values.

One combination of parameters $a, b, c, d$ and one combination of parameters $k, m, p$ were selected basing on the presumed criteria: the formulas described by these parameters were characterized by the lowest average relative error $\delta$ for all 29 test series. The best data explanation for laboratory database of I and II model was achieved in the following parameters values: $a=$ $7.41 ; b=0.38 ; c=-0.10 ; d=-0.45 ; k=0.34 ; m=0.01 ; p=-0.01$, thence the identified formulas, can be described as:

$$
\begin{gathered}
L_{s}=7.41 q^{0.38}\left(z_{\max }+h\right) d_{50}{ }^{-0.10} h^{-0.45} \\
L_{e}=0.34 L_{s} d_{50}{ }^{0.01} h^{-0.01}
\end{gathered}
$$

476

477

478

479

480

481

482

483

484

485

486

487

488

489

490

491

492

493

494

495

496

Optimization revealed a diminished error, both in the case of total scour length $L_{s}(10.1 \%)$ and for the distance between the deepest point of scour and the end of reinforcement $L_{e}(18.2 \%)$.

Verification of the optimized Straube formula was performed on independent data published in 2010 by Gaudio and Marion. In 1998, research was carried out in the Wallingford Ltd., a hydraulic laboratory, on the evolution of local scouring downstream the bed sills cascade. The flume consists of a $60 \mathrm{~cm}$-wide, $24.5 \mathrm{~cm}$-high and $5.57-\mathrm{m}$ working section with rectangular cross-section. For the full description of the duct, see Gaudio, Marion (2003). The bed sills used in all experiments were $25 \mathrm{~mm}$-thick by $15 \mathrm{~cm}$-high wooden plates, with the same width as the transversal section. The sediment used in all tests was sand with median diameter $d_{50}=1.8 \mathrm{~mm}$. No sediment recirculating system was adopted.

The similarity of Gaudio and Marion test stand and the flume, where present research was performed, come down to used bed material (sand), the shape of the flume (rectangular, 60-cm width), the same order or magnitude of unit discharges and the transversal type of water structure. The main difference is duration of each experimental series: in Gaudio and Marion, experiment series last much longer than the present one: from 45 to 90 hours. Gaudio carried out 12 series of measurements in order to obtain the geometric dimensions of local scour holes formed under given hydraulic conditions. The maximal depth $z_{\max }$ and the total length of the scour $L_{s}$ was studied. The hydraulic parameters of each measurement series and the geometric properties of the local scour are summarized in Table 6. Based on the results received, Straube formula was verified in its original and optimized in form by Monte Carlo sampling procedure (Eq. 13 and 20). A mean relative error $\delta=49.2 \%$ was obtained for the original form, whereas the application of the 
497

498

499

500

501

502

503

504

505

506

507

508

509

510

511

512

513

514

515

516

517

518

519

520

521

522

523

524

525

526

527

528

529

530

531

532

533

534

535

optimized Straube formula demonstrated a better description of the data obtained in the laboratory, characterized by an error mean relative $\delta$ equal to $18.1 \%$.

\section{Discussion}

The optimized Straube formula demonstrated very accurate laboratory dataset description, whereas the remaining equations analysis showed a relative error ranging up to more than $390 \%$. The Straube equations forms, which have been optimized for the laboratory workstation, have been validated for field data. Zagożdżonka River in Czarna (Poland) was built in the fifties of last century as a concrete hydraulic structure to store up the water and to use its energy to drive the mill wheel. The total width of the spill is divided by I-beam guides into 3 clear spans: $1.16 \mathrm{~m}$ wide outermost spans and 1.22 m center span (Figure $12 \mathrm{a}, \mathrm{b}$ ). In the guides, a measuring sharp-crested triangular weir was installed. The height and shape of the weir edges were developed to ensure non-submergence weir working conditions at the highest possible flow rates.

The downstream part of the structure consists of $8.80 \mathrm{~m}$ long concrete reinforcement with a longitudinal slope of $1 \%$, followed by a $0.60 \mathrm{~m}$ drop, so it could be recognized as similar to laboratory condition test models. The river bed, directly below the drop, is partially covered with a stone riprap over on a reach of about $1.0 \mathrm{~m}$, and in a further section it is scourable, made of sand, with $d_{50}$ diameter of $0.42 \mathrm{~mm}$ and $d_{90}$ diameter of $0.74 \mathrm{~mm}$.

On June 11 2013, a flood occurred. The flow rate in the hydrograph peak reached $5.06 \mathrm{~m}^{3} \mathrm{~s}^{-1}$. This event resulted in local scour formation downstream the weir, whose dimensions were measured, analyzed and published by Urbański and Hejduk (14). Field measurements performed the following local scour dimensions:

-- water depth above the deepest scour point $H_{\max }=z_{\max }+h=2.43 \mathrm{~m}$;

-- local scour length $L_{s}=13.8 \mathrm{~m}$;

-- the distance between the deepest point of scour and the end of reinforcement $L_{e}=5.20 \mathrm{~m}$.

In the case of water depth $H_{\max }$ calculations an error of $39.5 \%$ was achieved using the Rossinski formula with a $k_{1}$ parameter equal to 1.70 (Eq.1) (Table 7). The best fit of the measurement and calculations was obtained for Müller equations, where measured scour length and the distance between the deepest point of scour from the end of reinforcement rare within the ranges described in equations no. 8 and 10 (an error of $0 \%$ ). In the case of default form of Straube equations, $57.2 \%$ of an error was achieved for scour length $L_{s}$ analysis and $7.7 \%$ for the $L_{e}$ distance.

An optimized form of Straube equations (20), (21) were checked on the field measurements. Calculations using the Straube's optimized formula showed excellent adherence for the measured and calculated value of the local bottom scour length (an error equal to $0.2 \%$ ). However, the distance of the maximum hole depth from the end of the reinforcement was underestimated and the underestimation amounted to $16.6 \%$ of this value. A common observation for laboratory and field tests is the overestimation of both parameters using the Tajarmovič formula.

\section{Conclusions}


536

537

538

539

540

541

542

543

544

545

546

547

548

549

550

551

552

553

554

555

556

557

558

559

560

561

562

563

564

565

566

567

568

569

570

571

572

573

574

Two gated check models were investigated in water discharge flowing out from under the gate, characterized by different roughness of the reinforcement downstream, followed by scourable bed. 29 measurement series were performed in total, each lasting 8 hours. The basic geometrical parameters of local scour hole, resulting from the disturbance of hydrodynamic balance of the system were examined using autonomic remote-controlled measuring unit. The construction of the tested models was chosen due to the prevalence of such solutions among real objects.

10 computational formulas, used for many years in the water engineering practice, were verified for laboratory data. It was stated that functions based only on one $\left(z_{\max }\right)$ or two $\left(z_{\max }, h\right)$ parameters provide weaker adjustment between calculations results and laboratory measurements. The Straube's formula, assuming that geometric parameters follow up on not only maximal scour depth and water level, but also granulometric parameters, represented by medium grain diameter $d_{50}$ and hydraulic properties of experiment, such as unit discharge $q$ was distinguished as the best description of laboratory test results.

The Straube function demonstrated the mean relative error of $34.2 \%$ in the case of comparing the measurement and calculation result of the local scour depth and an error of $32.1 \%$ for the distance of the deepest point from the end of the reinforcement, while medium error for all the rest of formulas was $67 \%$ for $L_{s}$ and $133 \%$ for $L_{e}$.

The Monte Carlo sampling method allowed the original formulas to be adapted to calculate the local scour geometrical parameters downstream the model of the gated check. In optimizing the parameters, the criterion of minimizing the relative error was applied. The Monte Carlo sampling procedure resulted in a much better match between the calculation results and the dimensions measured in the laboratory: Straube function optimized in this way demonstrated an error of $10.1 \%$ in the case of comparing the measurement and the calculation of the local scour length and an error of $18.2 \%$ for the distance of the deepest point from the end of the reinforcement.

The Straube's formula, chosen as the best describing laboratory results, was verified on independent dataset, whose main features in common with present experiment characteristics are: used bed material (sand), the shape of the flume, the same order or magnitude of unit discharges and the transversal type of water structure. A mean relative error $\delta=49.2 \%$ was obtained for the original form of the Straube formula, and $18.1 \%$ for optimized formula using the Monte Carlo sampling method. Due to the data availability, only the total length of the scour was compared.

The optimized for laboratory measurements equation was checked for the real object, which was selected on the basis of the similarity of the downstream reinforcement, and of the data availability. It should be emphasized that field measurements of the bottom shape after the formation of local scour hole are often difficult to access due to the imperfection of measuring instruments and lack of data before the formation of a local scour. The optimization led to obtain an error of $0.2 \%$ for scour length and an error of $16.6 \%$ for the distance of the deepest point from the end of the reinforcement.

The extension of the optimized Straube formula verification to other hydro-technical field objects is necessary for the applicability of the investigation, however it has to be stated that very

Peer) reviewing PDF | (2020:03:46700:1:1:NEW 3 Sep 2020) 
575 high degree of adjustment of calculation results to field data (especially local scour length) provide 576 an encouraging premise for further research.

577

\section{Acknowledgements}

579 This research was supported by Department of Hydrotechnics and Technology and Department 580 of Water Engineering and Applied Geology, Warsaw University of Life Sciences WULS -

581 SGGW, Poland. The applied device was engineered in 2016 by Marta Kiraga and Matvey

582 Razumnik within the university grant "The influence of small hydraulic structures on sediment 583 transport condition".

\section{References}

585

586 Ahmad M. 1953. Experiments on design and behaviour of spur-dikes. Minnesota International 587 Hydraulics Convention Proceedings: 145-159

588 Al-Husseini TR, Al-Madhhachi AST, \& Naser ZA. 2019. Laboratory experiments and numerical 589 model of local scour around submerged sharp crested weirs. Journal of King Saud University 590 Engineering Sciences: 1 - 10 DOI: 10.1016/j.jksues.2019.01.001.

591 Al-Mohammed FM, Jassim AT, Abbass HA. 2019. An experimental and numerical study of 592 factors influencing the scour due to the collision of water jet in stilling basin floor. Kufa Journal 593 of Engineering 10(2): 42 - 59 DOI: 10.30572/2018/kje/100204.

594 AL-Suhaili RH, Abbood DW, Samir Saleh M. 2017. Optimum dimensions of hydraulic

595 structures and foundation using genetic algorithm coupled with artificial neural network. Journal 596 of Engineering 9(23): 1-22 DOI: 10.13140/RG.2.2.18186.77765.

597 Bajkowski S, Siwicki P, Urbański J. 2002. Utilization of laboratory investigations of local scour 598 below water structures to estimate their safety. Acta Scientiarum Polonorum Seria Architectura 599 1:41-51.

600 Barbhuiya AK, Dey S. 2004. Local scour at abutments: A review. Sadhana 29: 449-476.

601 Ben Meftah M, Mossa M. 2006. Scour holes downstream of bed sills in low-gradient channels.

602 Journal of Hydraulic Resources 44:497-509 DOI: 10.1080/00221686.2006.9521701.

603 Boix D, Biggs J, Céréghino R, Hull AP, Kalettka T, Oertli B. 2012. Pond research and

604 management in Europe: "Small is Beautiful." Hydrobiologia 689(1): 1-9 DOI: 10.1007/s10750-

605 012-1015-2.

606 Brandimarte L, Paron D, Di Baldasarre D. 2012. Bridge pier scour: A review of processes, 607 measurements and estimates. Environmental Engineering and Management Journal 11: 975-989 608 DOI: 10.30638/eemj.2012.121.

609 Breusers HC, Raudkivi AJ. 1991. Scouring: Hydraulic Structures Design Manual Series Vol 2. 610 London: Taylor \& Francis.

611 Chabert J, Engeldinger P. 1956. Etude des affouillements autour des piles des ponts. Study on 612 scour around bridge piers. Chatou: Laboratoire National d'Hydraulique. 
613 Chen SH. 2015. Planning and design of hydraulic projects. In: Chen SH, ed. Hydraulic

614 Structures. Berlin: Springer, 41-93 DOI: 10.1007/978-3-662-47331-3_2.

615 Cullen RT. 1991. Vortex mechanisms of local scour at model fishrocks. Fisheries

616 Bioengineering Symposium: American Fisheries Society Symposium 10: 213:218.

617 Epely-Chauvin G, De Cesare G \& Schwindt S. 2014. Numerical modelling of plunge pool scour

618 evolution in non-cohesive sediments. Engineering Applications of Computational Fluid

619 Mechanics 8(4): 477-487 DOI: 10.1080/19942060.2014.11083301.

620 Farhoudi J, Smith KV. 1985. Time scale for scour downstream of hydraulic jump. Journal of

621 Hydraulic Resources 23:343-358.

622 Franke PG. 1960. Über Kolkbindung und Kolkformen. Östereeichische Wasserwirtschaf 1.

623 Gaudio R, Marion A. 2003. Time evolution of scouring downstream of bed sills. Journal of

624 Hydraulic Research 41(3): 271-284 DOI: 10.1080/00221680309499972.

625 Graf WH. 1998. Fluvial hydraulics. Chichester: John Wiley \& Sons Ltd, 611-645.

626 Hauer C, Leitner P, Unfer G, Pulg U, Habersack H, Graf W. 2018. The role of sediment and 627 sediment dynamics in the aquatic environment. In: Schmutz S, Sendzimir J, eds. Riverine

628 Ecosystem Management. Aquatic Ecology Series 8. Cham: Springer, 151-169 DOI: 10.1007/978629 3-319-73250-3_8.

630 Hockley F, Wilson C, Brew A, Cable J. 2013. Fish responses to flow velocity and turbulence in 631 relation to size, sex and parasite load. Journal of The Royal Society Interface 11: 20130814.

632 Hossain GMA. 1992. Diagnostic study of failures of hydraulic structures in Bagladesh - case

633 studies of failures in Chattagong district. M. Sc. Thesis, Bangladesh University of Engineering 634 and Technology.

635 Jaboyedoff M, Oppikofer T, Abellán A, Derron MH, Loye A, Metzger R, Pedrazzini A. 2010.

636 Use of LIDAR in landslide investigations: a review. Natural Hazards 61(1): 5-28 DOI:

637 10.1007/s11069-010-9634-2

638 Jordaan JM. 2009. Design of sustainable hydraulic structures. In: Jordan JM, Bell A, eds.

639 Hydraulic structures, Equipment and Water Data Acquisition systems. Vol. II. Oxford: Eolss

640 Publishers Company Limited, 163 - 178.

641 Khaple S, Hanmaiahgari PR, Gaudio R, Dey S. 2017. Splitter plate as a flow-altering pier scour 642 countermeasure. Acta Geophysica 65(5): 957-975 DOI: 10.1007/s11600-017-0084-z.

643 Killinger DK. 2014. Lidar (light detection and ranging). Laser Spectroscopy for Sensing 10: 292644 312 DOI: 10.1533/9780857098733.2.292.

645 Kiraga M., Popek Z. 2016. Using a modified Lane's relation in local bed scouring studies in the

646 laboratory channel. Water 8: 16. https://doi.org/10.3390/w8010016.

647 Kiraga MJ, Razumnik M, Popek Z, Chmielewski L. 2018. Applying laser scanning technology to

648 studying alluvial flume-bed topography in laboratory conditions. Acta Scientiarum Polonorum

649 Formatio Circumiectus 17:69-84.

650 Kiraga M., Popek Z. 2018. Geometry description of local scouring process in various laboratory 651 water structure models. In: Kalinowska M, Mrokowska M, Rowiński P, eds. Free Surface Flows 
652 and Transport Processes. GeoPlanet: Earth and Planetary Sciences. Cham: Springer, 245-258 653 DOI: 10.1007/978-3-319-70914-7_15.

654 Kiraga M., Popek Z. 2019. Bed shear stress influence on local scour geometry properties in various 655 flume development conditions. Water 11: 2346 DOI: 10.3390/w11112346.

656 Kiraga M., Miszkowska A. 2020. Lane's relation in local scour investigations. IEEE Access 8: 657146967 - 146975 DOI: 10.1109/ACCESS.2020.3013275

658 Kobus H, Koschitzky HP. 1991. Local Surface aeration at hydraulic structures. In: Wood IR, ed. 659 Air entrainment in free-surface flows. IAHR Hydraulic Structures Design Manual, Rotterdam:

660 A.A. Balkema, 29-54.

661 Koskinen K, Leino T, Riipinen H. 2008. Sustainable development with water hydraulics662 possibilities and challenges. Proceedings of the JFPS International Symposium on Fluid Power 663 2008:11-18 DOI: 10.5739/isfp.2008.11.

664 Kraatz DB, Mahajan IK. 1975. Small hydraulic structures. Rome: Food and Agriculture 665 Organization of the United Nations, 32.

666 Lacey G. 1946. A general theory of flow in Alluvium. Journal of the Institution of Civil 667 Engineers 27(1): 16-47 DOI: 10.1680/ijoti.1946.13786.

668 Lajczak A. 1996. Reservoir sedimentation problems in the Vistula River basin, Poland. Erosion 669 and Sediment Yield: Global and Regional Perspectives (Proceedings of the Exeter Symposium, 670 July 1996). IAHS Publication 236:501 - 511.

671 Lee SO, Hong SH. 2019. Turbulence characteristics before and after scour upstream of a scaled672 down bridge pier model. Water 11(9): 1900 DOI: 10.3390/w11091900.

673 Lenzi MZ, Marion A., Comiti F. 2003. Local scouring at grade-control structures in alluvial 674 mountain rivers. Water Resources Research 39: 1176-1188 DOI: 10.1029/2002WR001815.

675 Li H, Li H, Jin P, Yang Y. 2020. Flexible flow deflectors against local scour at bridge piers. IOP

676 Conference Series: Materials Science and Engineering 768: 032018 DOI: 10.1088/1757-

$677899 x / 768 / 3 / 032018$.

678 Liao JC, Cotel A. 2013. Effects of turbulence on fish swimming in aquaculture. In: Palstra AP, 679 Planas JV, eds. Swimming physiology of fish: towards using exercise to farm a fit fish in 680 sustainable aquaculture. Berlin: Springer-Verlag, 109 - 127 DOI: 10.1007/978-3-642-31049681 2_5.

682 Lopardo RA, Seoane R. 2004. Floods control in Argentina: learning from the experience. In:

683 Greco M, Carravetta A, Della Morte R, eds. River Flow 2004. London: Taylor \& Francis Group, 684 1403-1409.

685 Lupandin AI. 2005. Effect of flow turbulence on swimming speed of fish. Bulletin of the Russian 686 Academy of Sciences 32: 461-466 DOI:10.1007/s10525-005-0125-z.

687 Mioduszewski W. 2014. Small (natural) water retention in rural areas. Journal of Water and 688 Land Development 20(I-III): 19-29.

689 Niederreiter H. 1992. Random number generation and quasi-Monte Carlo methods. Philadelphia, 690 USA: Society for Industrial and Applied Mathematics, 1-12. 
691 Nouri Imamzadehei A, Heidarpour M, Nouri Imamzadehei M, Ghorbani B, Haghiabi A. 2016. 692 Control of the local lcouring sround the cylindrical bridge pier using armed soil by geotextile. 693 International Journal of Geosynthetics and Ground Engineering 2(5): 1-8 DOI:

694 10.1007/s40891-016-0045-7.

695 Ochman D, Kaszubkiewicz J. 2004. Change of water oxygenation state in the vicinity of dam 696 plants on the Smortawa river example. Quarterly of Environmental Engineering and Design 131: 697 287-293.

698 Odgaard AJ. 2017. River management with submerged vanes. In: Sharma N, ed. River System 699 Analysis and Management. Singapore: Springer Nature, 251 - 262 DOI: 10.1007/978-981-10700 1472-7_13.

701 Pagliara S, Kurdistani SM. 2013. Scour downstream of cross-vane structures, Journal of Hydro702 environment Research 7(4): 236-242 DOI: 10.1016/j.jher.2013.02.002.

703 Pagliara S, Radecki-Pawlik A, Palermo M, Plesiński K. 2016. Block ramps in curved rivers: 704 morphology analysis and prototype data supported design criteria for mild bed slopes. River 705 Resources and Applications 33: 427-437 DOI: 10.1002/rra.

706 Prendergast LJ, Gavin K. 2014. A review of bridge scour monitoring techniques. Journal of Rock 707 Mechanics and Geotechnical Engineering 6:138-149 DOI: 10.1016/j.jrmge.2014.01.007.

708 Rasekh A, Afshar A, Afshar MH. 2010. Risk-cost optimization of hydraulic structures:

709 methodology and case study. Water Resources Management 24(11): 2833-2851 DOI:

710 10.1007/s11269-010-9582-3.

711 Rossinski KI, Kuzmin IA. 1969. Opyt projektirovanija miestnych razmyvov v niżnich bjefach

712 gidrouzlov. In: Rabota niżnich bjefov gidrotechničeskich soorużenij. Moskva: Kolos.

713 Singh NB, Devi TT, Kumar B. 2020. The local scour around bridge piers - a review of remedial

714 techniques. ISH Journal of Hydraulic Engineering, 1-14 DOI:

715 10.1080/09715010.2020.1752830.

716 Siwicki P, Urbański J. 2004. Local scour below water structures and their influence on

717 environment. Acta Scientiarum Polonorum. Architectura 3(2): 113-120.

718 Smith DL, Goodwin RA, Nestler JM. 2014. Relating turbulence and fish habitat: a new approach

719 for management and research. Reviews in Fisheries Science \& Aquaculture 22(2): 123-130 DOI:

$72010.1080 / 10641262.2013 .803516$.

721 Straube C. 1963. Die Kolkbindung hinter underströmten Wehren. In: Mitteilungen der

722 Firschunsanstalt für Schiffahrt. Berlin: Wasser und Grundbau.

723 Sun DP, Wang LS, Wang PT. 2012. Study on the local scouring of the bridge with sediment

724 control dam. Applied Mechanics and Materials 204-208: 2230-2235 DOI:

725 10.4028/www.scientific.net/amm.204-208.2230.

726 Syvitski J, Slingerland R, Burgess P, Meiburg E \& Murray AB, Wiberg P, Tucker G, Voinov A. 727 2010. Morphodynamic models: an overview. River, Coastal and Estuarine Morphodynamics, 728 RCEM 2009: 3-20. 
729 Szydłowski M, Zima P. 2006. Two-dimensional vertical Reynolds-averaged Navier-Stokes

730 equations versus one-dimensional Saint-Venant model for rapidly varied open channel water

731 flow modelling. Archives of hydro-Engineering and Environmental Mechanics 53(4): 295-309.

732 Ślizowski R, Radecki-Pawlik A. 2003. Verification of formulae for calculating scour below

733 hydraulic structure using laboratory results. Acta Scientiarum Poonorum Formatio Circumiectus

734 2:25-34.

735 Taha N, El-Feky MM, El-Saiad AA \& Fathy I. 2020. Numerical investigation of scour

736 characteristics downstream of blocked culverts. Alexandria Engineering Journal 1-11 DOI:

737 10.1016/j.aej.2020.05.032.

738 Tarajmovič II. 1966. Krieplenije v niżniem bjefie vodoslivnych plotin. Moskva: Energija.

739 Urbański J. 2008. Influence of roughness of bed protection downstream of weir on local scour.

740 Scientific Review - Engineering and Environmental Sciences 2(40): 169-177.

741 Urbański J, Hejduk L. 2014. Analysis of sizes of local scour as a result of flood. Monografie

742 komitetu gospodarki wodnej PAN XX: 389-400.

743 Wang L, Melville BW, Shamseldin AY \& Nie R. 2020. Impacts of bridge piers on scour at

744 downstream river training structures: submerged weir as an example. Water Resources Research:

745 e2019WR026720 DOI: 10.1029/2019wr026720

746 Yan X, Rennie CD, Mohammadian A. 2020. Numerical modeling of local scour at a submerged

747 weir with a downstream slope using a coupled moving-mesh and masked-element approach.

748 International Journal of Sediment Research DOI: 10.1016/j.ijsrc.2020.06.007

749 Zobeyer H, Jahan N, Islam Z, Singh G, Rajaratnam N. 2010. Turbulence characteristics of the

750 transition region from hydraulic jump to open channel flow. Journal of Hydraulic Research

751 48(3): 395 - 399 DOI: 10.1080/00221681003726320. 
Figure 1

Gated check details

(a) - model I (gated check without additional roughness downstream); (b) - model II (gated check with additional roughness downstream). 
a)

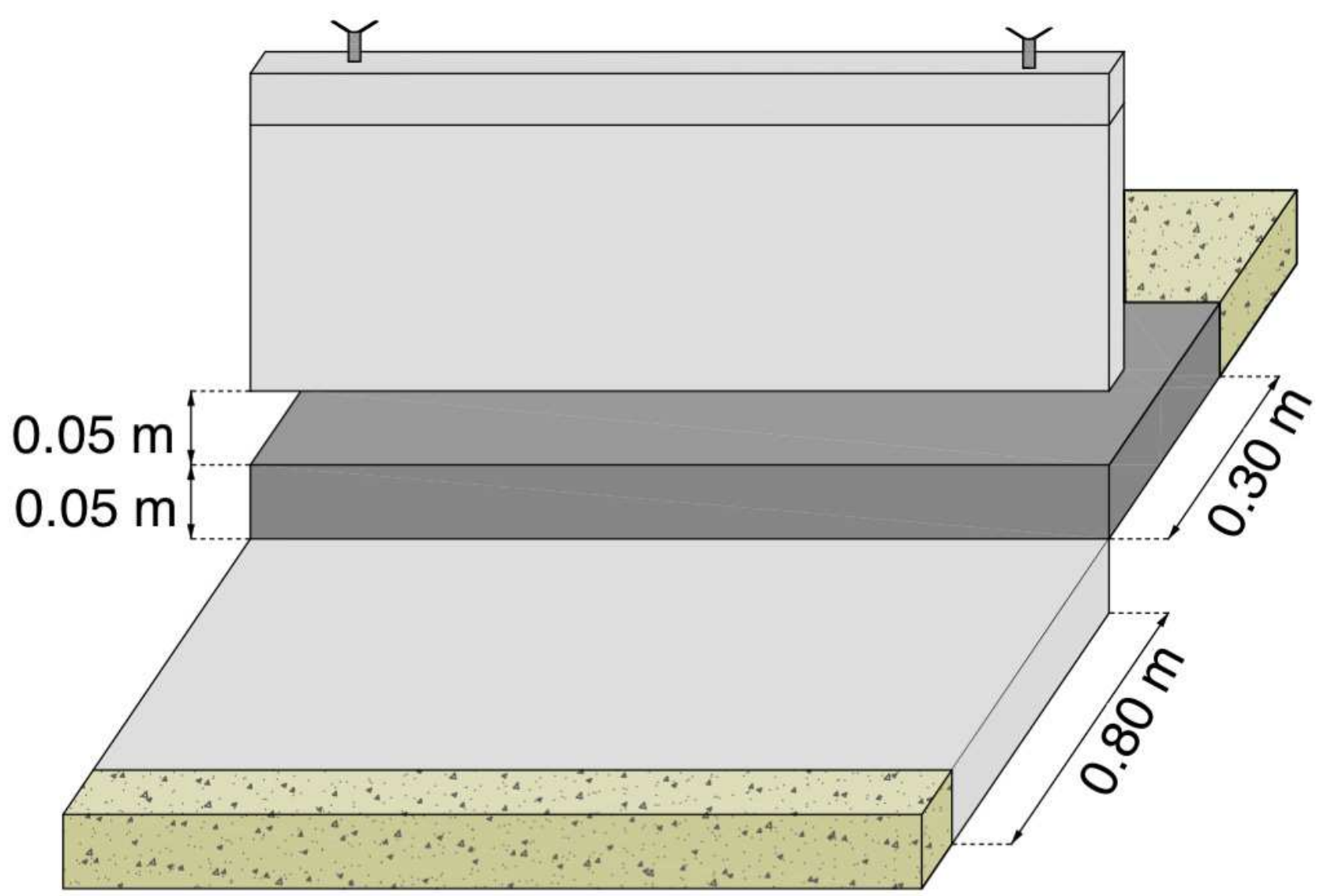

b)

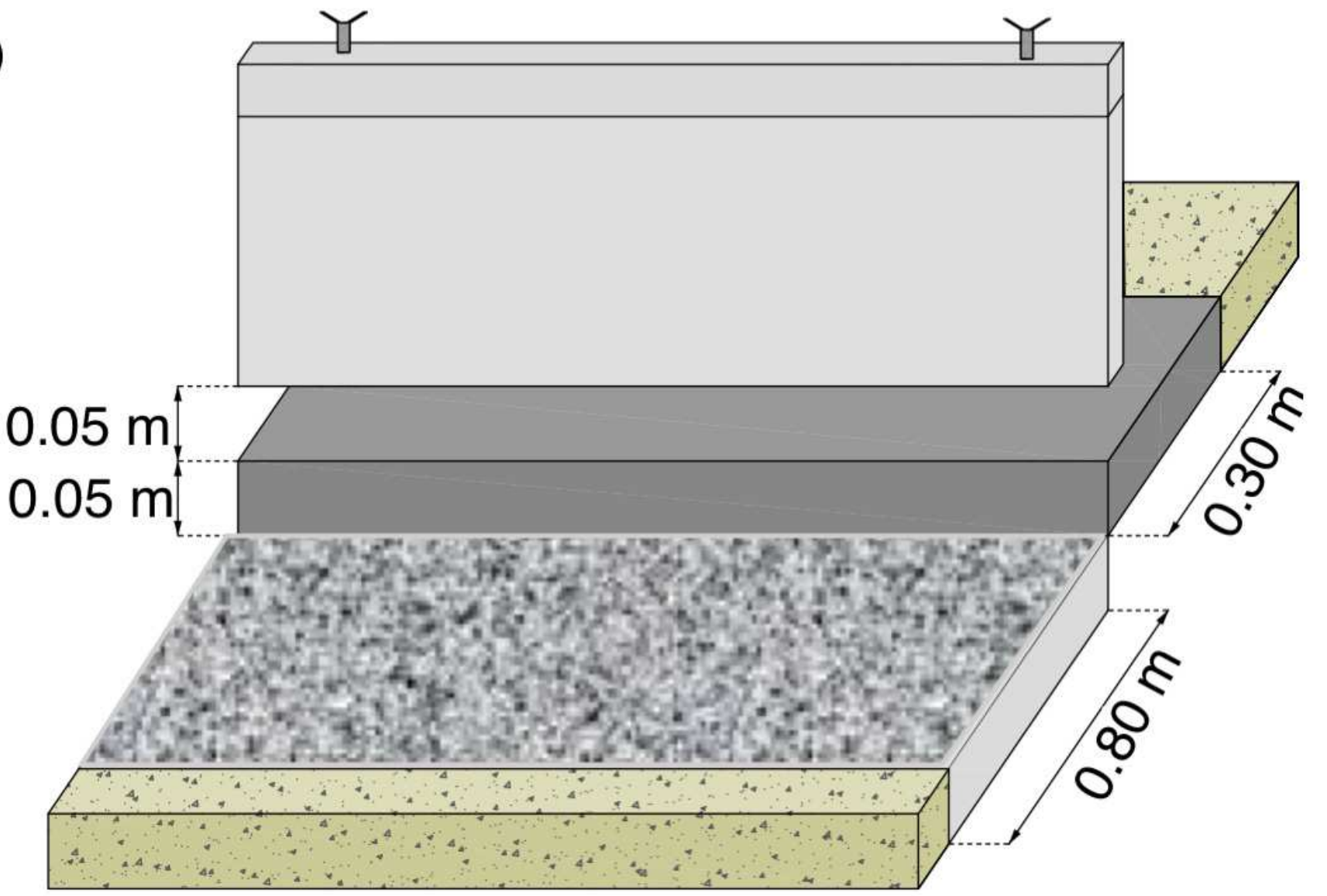

Peer] reviewing PDF | (2020:03:46700:1:1:NEW 3 Sep 2020) 


\section{Figure 2}

\section{Laboratory test stand}

(a) - model I (gated check without additional roughness); (b) - model II (gated check with additional roughness), where: 1 - movable pin gauge equipped with disc probe; 2 - sandy bed; 3 - gate; 4 - reinforcement; 5 - drainage; 6 - outlet gate; 7 - laser scanner; 8 reinforcement with additional roughness.

a)

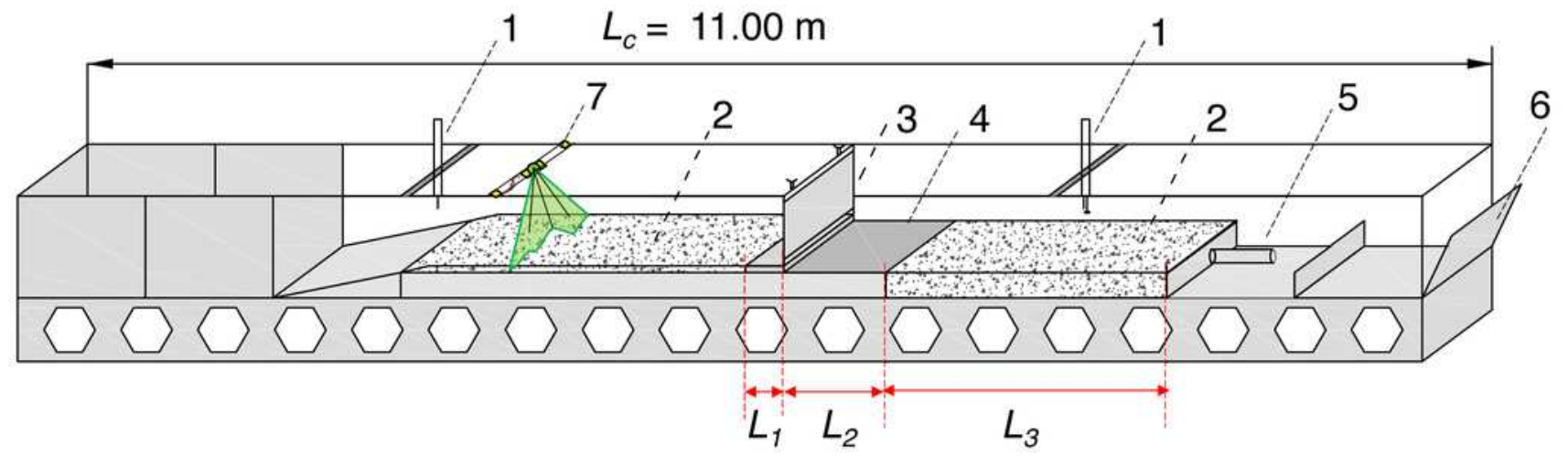

b)

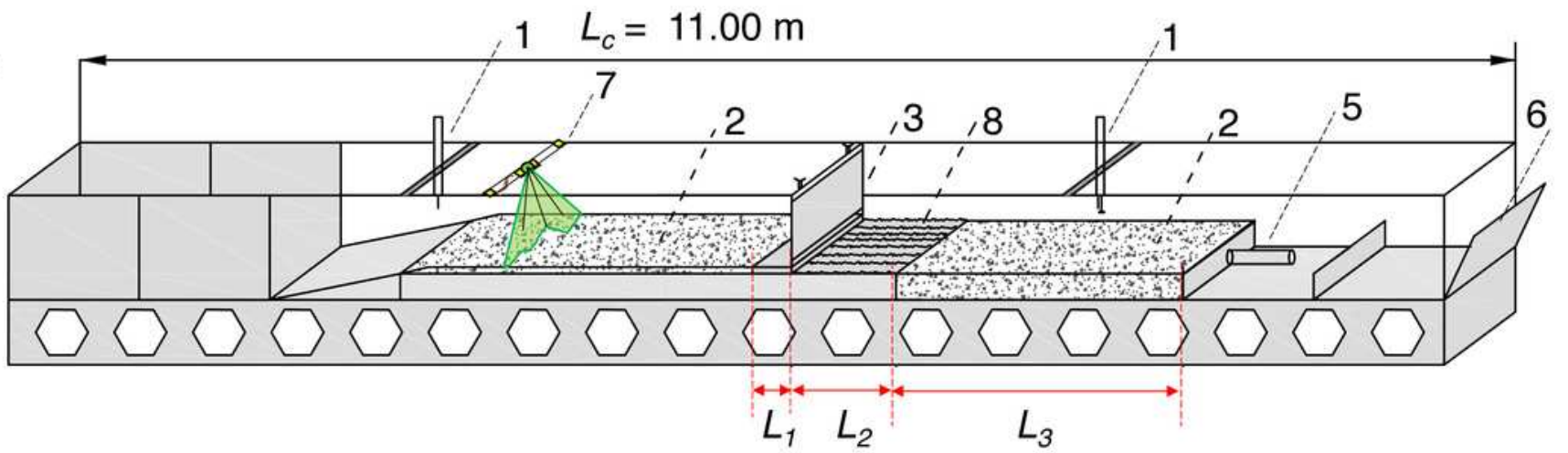




\section{Figure 3}

Photography of laboratory model

(a) - model I; (b) - model II.

a)

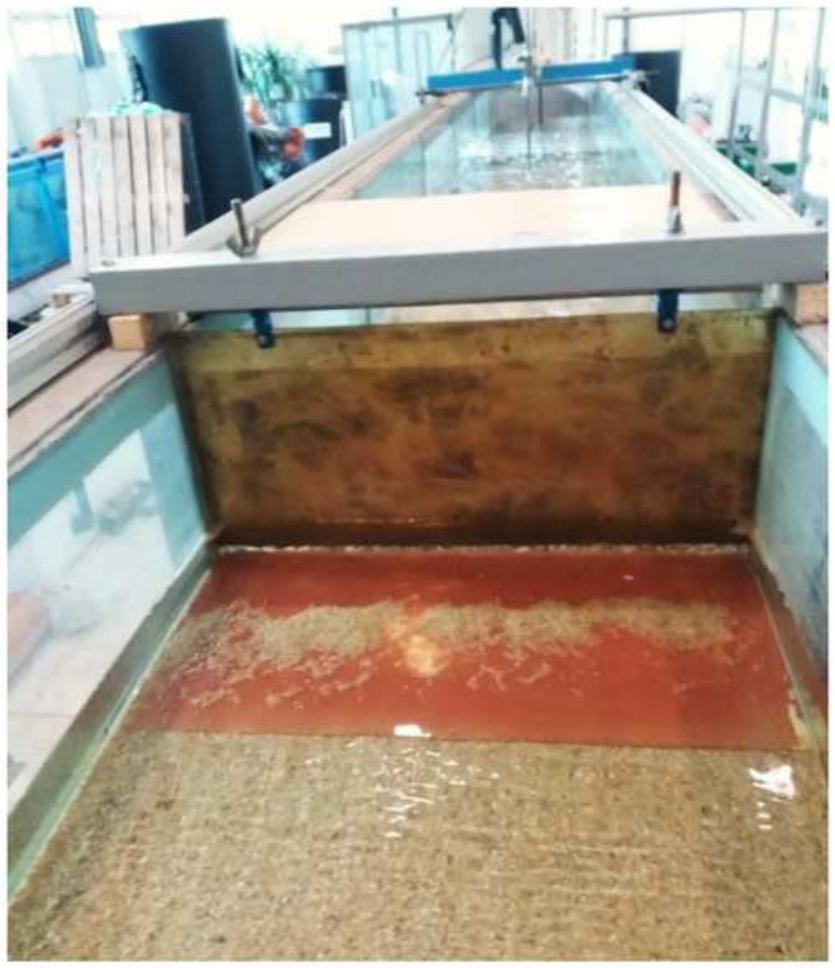

b)
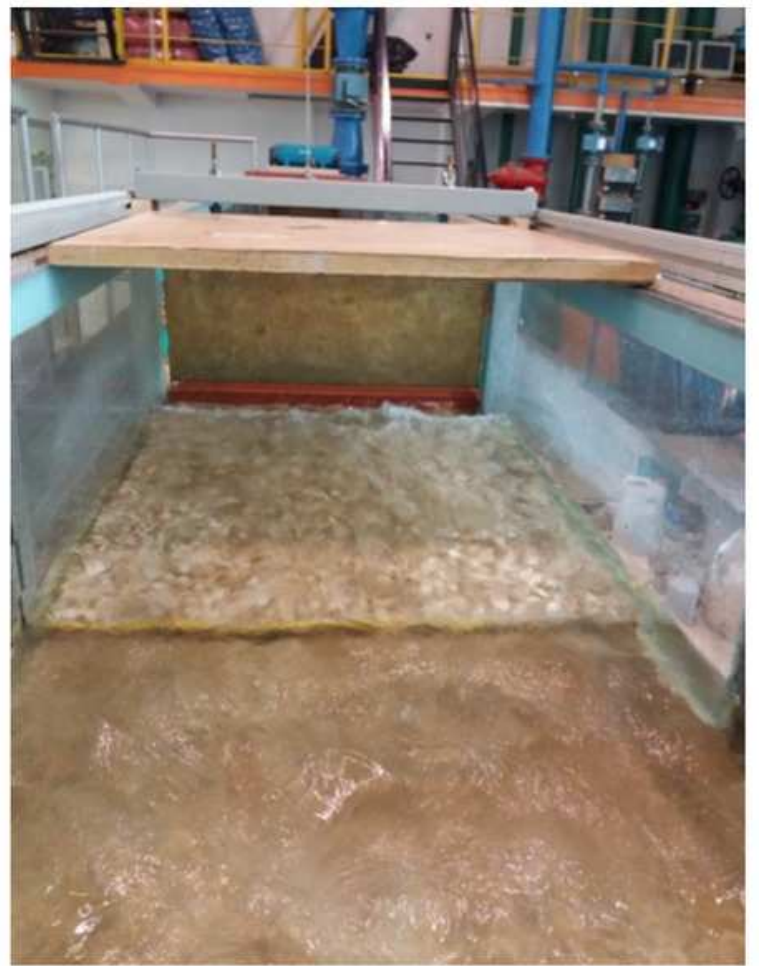
Figure 4

Local scour geometrical parameters

$Z_{\max }$ - maximal scour depth; $\mathrm{h}$ - water depth before scour formation; $L_{s}-$ scour length; $L_{\mathrm{e}}-$ the distance between the deepest point of the hole and the end of reinforcement

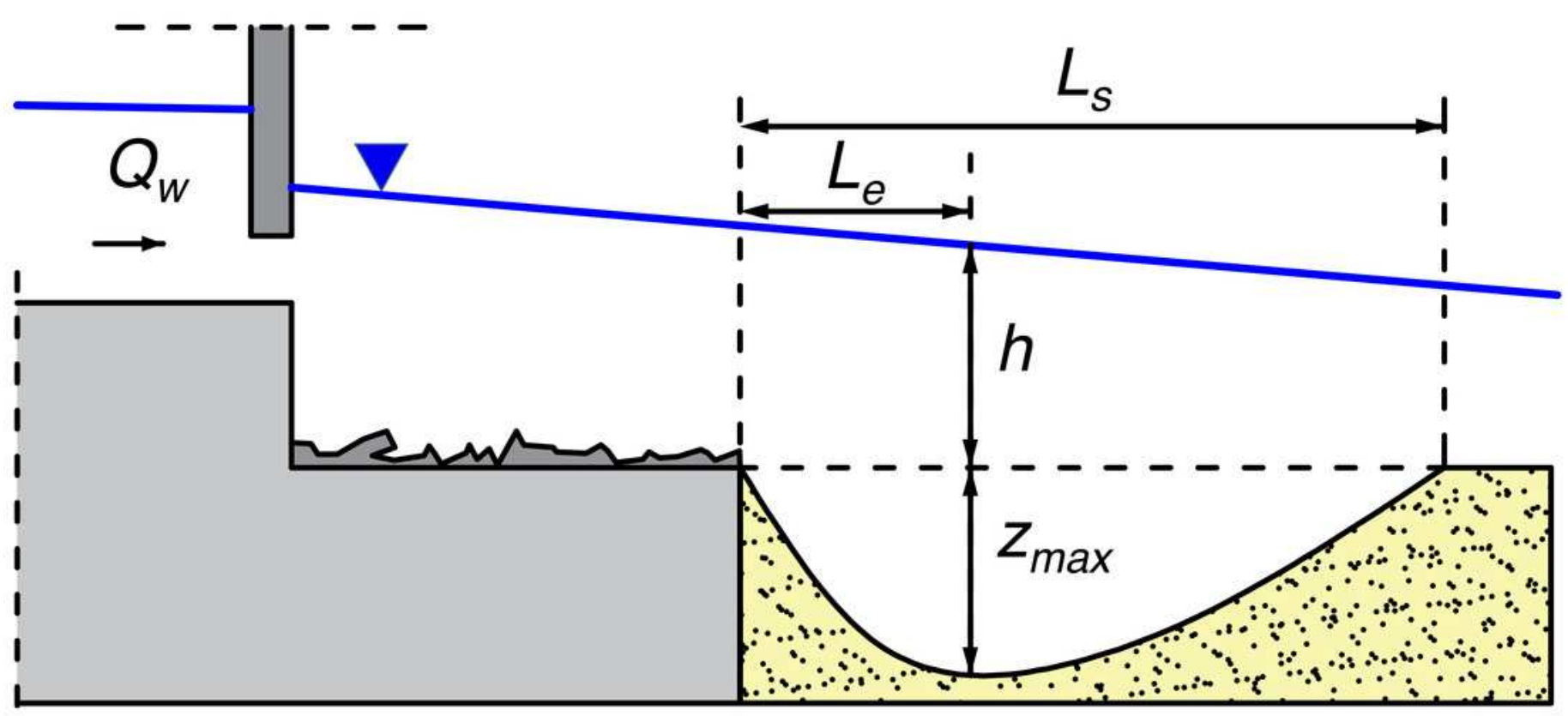

I 
Figure 5

Prototype A1 during laboratory measurements.

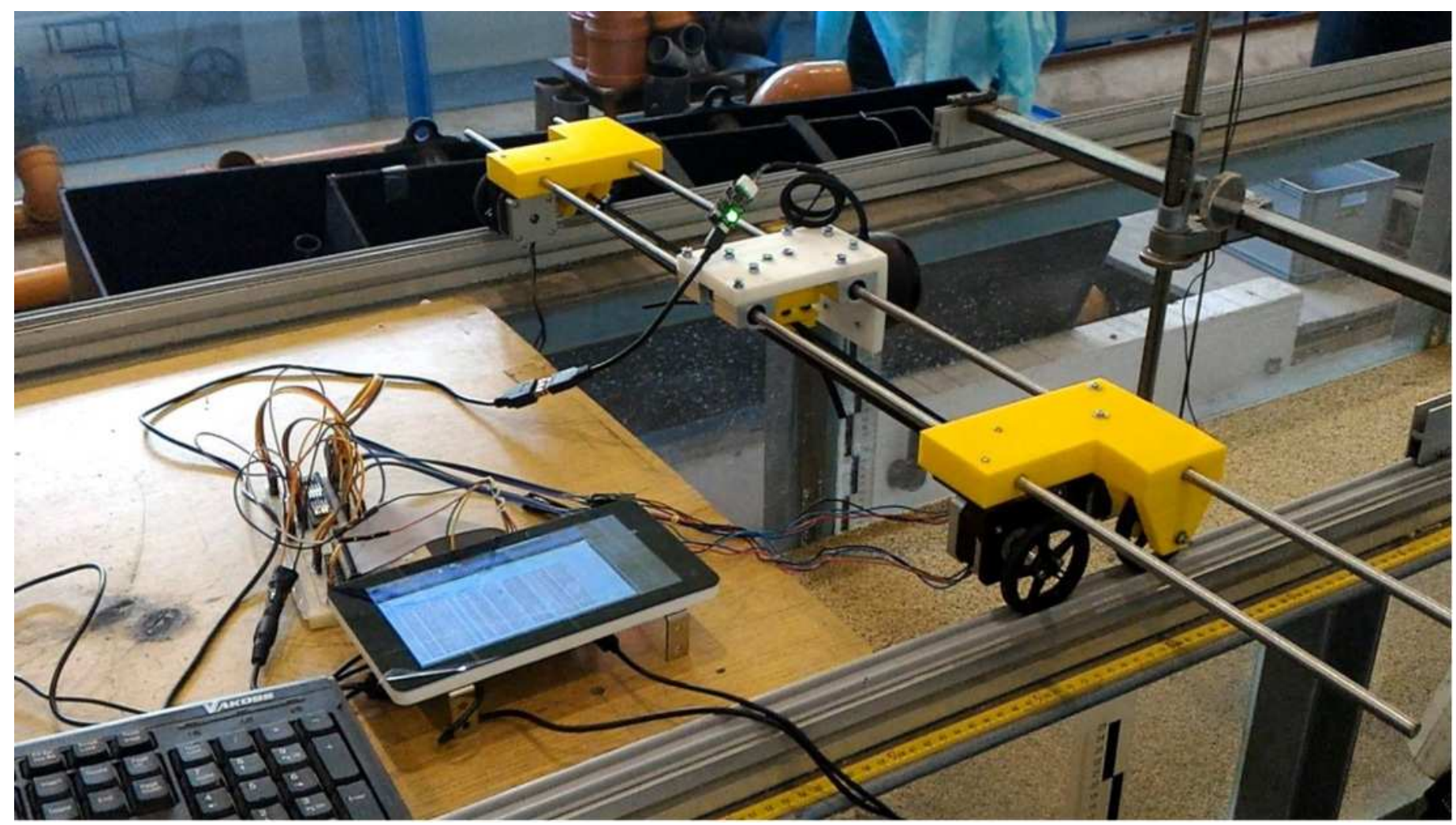




\section{Figure 6}

Various types of lower stage of gated check construction

a) reinforcement equipped with sheet piling, b) reinforcement followed by transversal trench

c) sandy bed following reinforcement with lowered bottom, where: 1 - gate; 2 - solid bottom;3 - stone reinforcement; 4 - sandy bed; 5 - sheet pilling or palisade; 6 - bank reinforcement; 7 - transverse trench with stone bottom; 8 - lowered reinforcement. 
a)

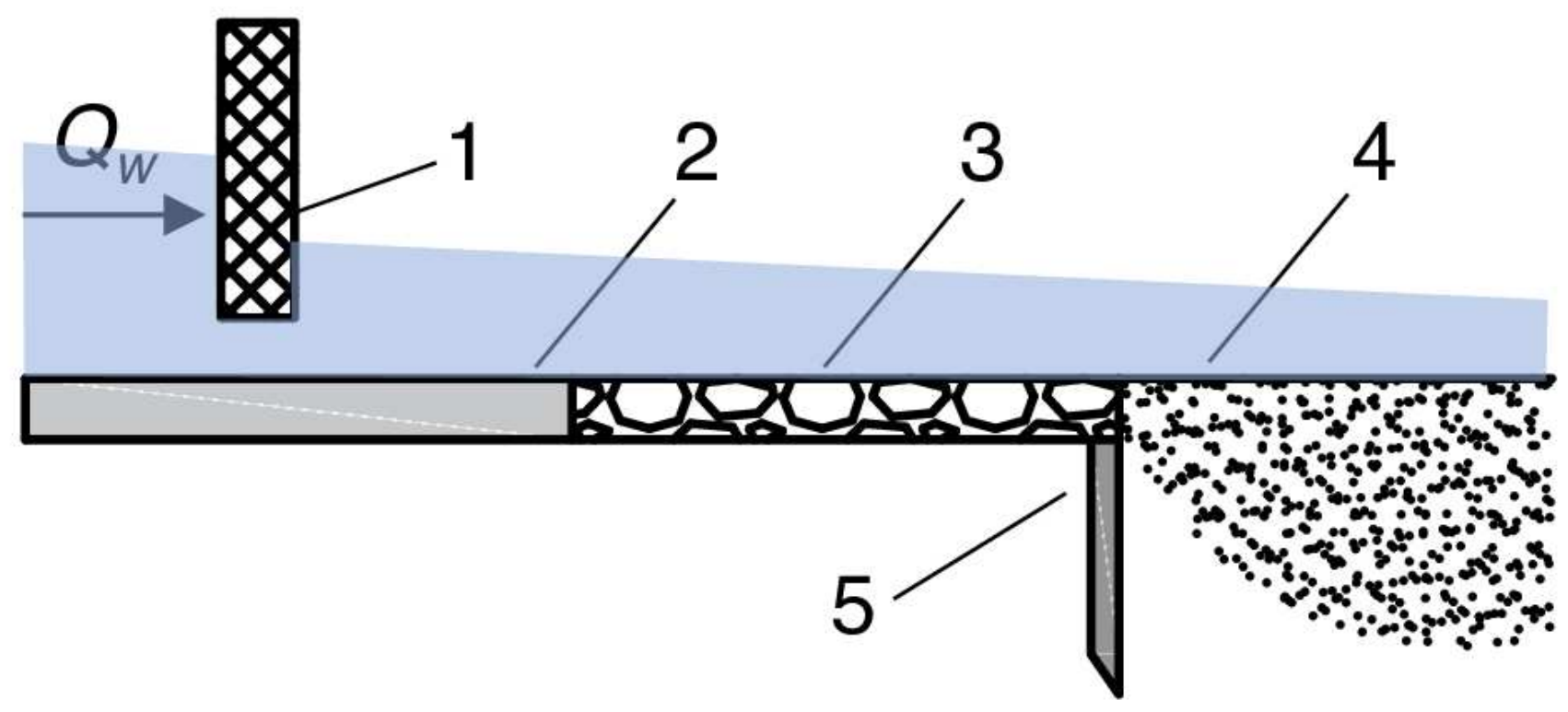

b)

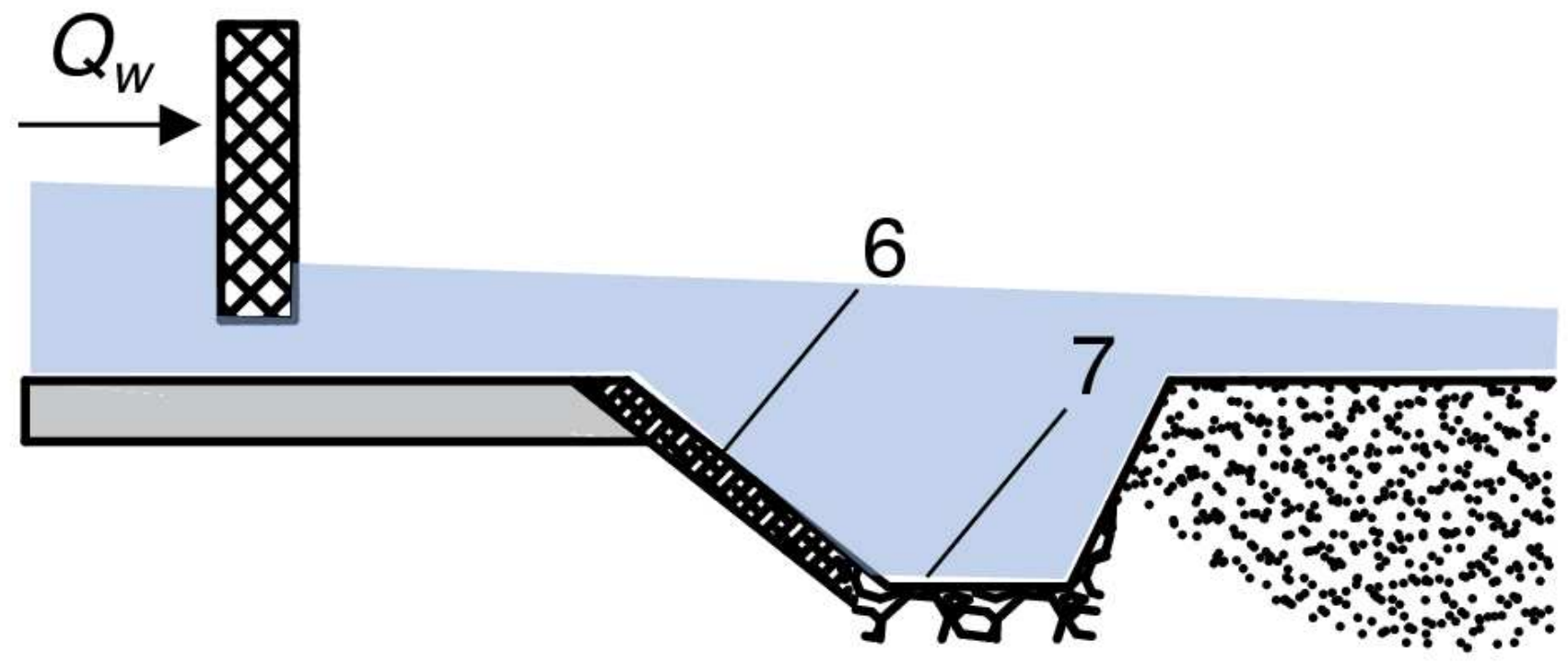

c)

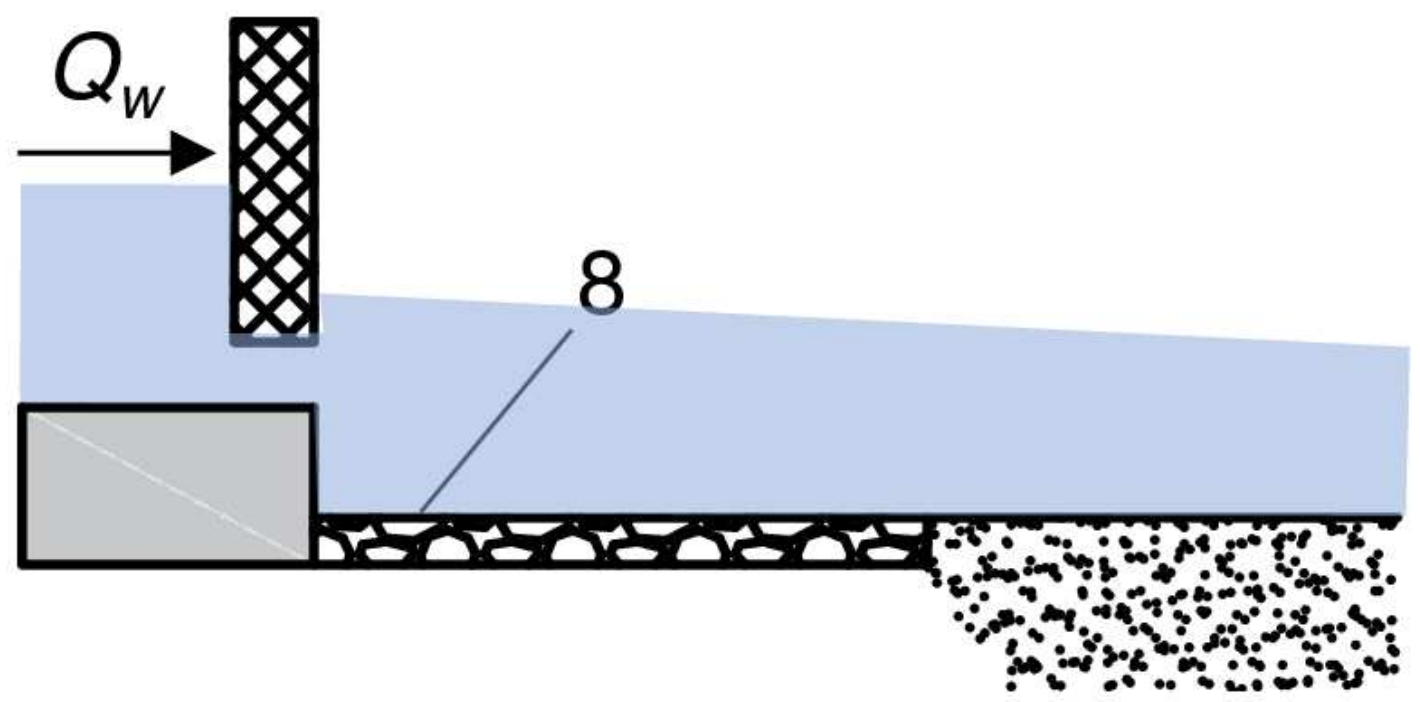


Figure 7

Shape the local scour downstream of the bed reinforcement in the Model II flume development during additional supplementary measurements. 
a) $Q_{w}=0.020 \mathrm{~m}^{3} \mathrm{~s}^{-1} \quad h=0.05 \mathrm{~m} \quad q=0.0345 \mathrm{~m}^{3} \mathrm{~s}^{-1} \mathrm{~m}^{-1}$

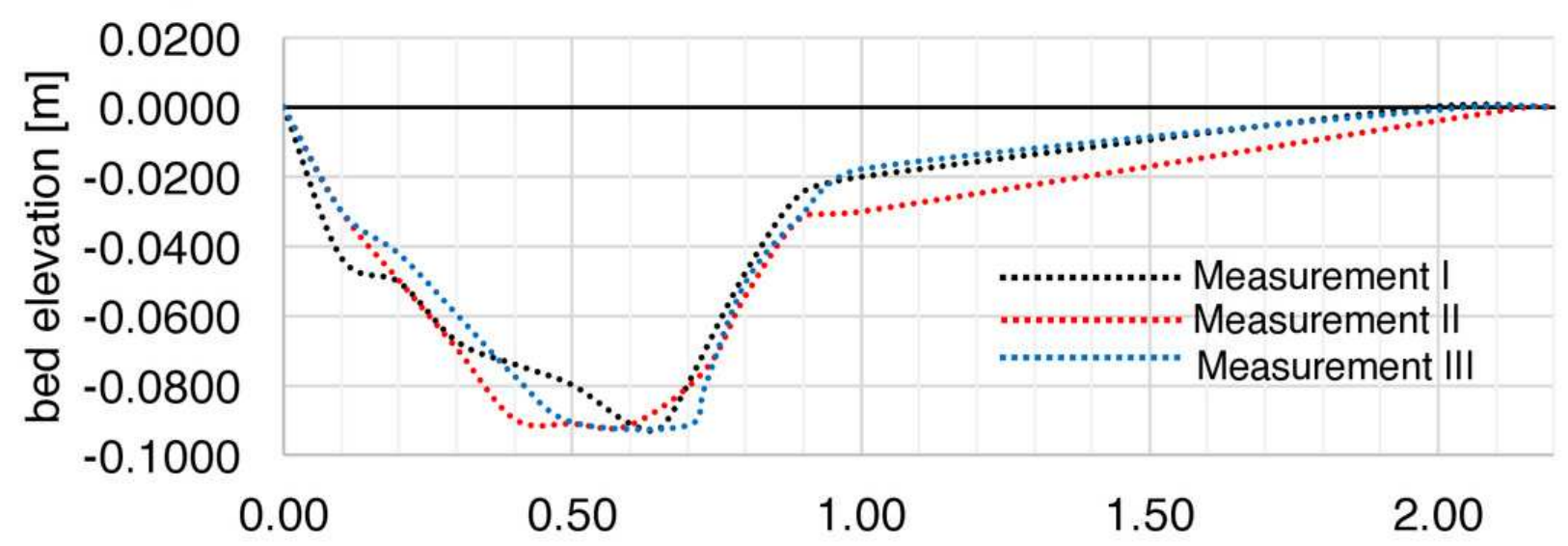

sandy bed length downstream the reinforcement [m]

b) $Q_{w}=0.030 \mathrm{~m}^{3} \mathrm{~s}^{-1} \quad h=0.08 \mathrm{~m} \quad q=0.0517 \mathrm{~m}^{3} \mathrm{~s}^{-1} \mathrm{~m}^{-1}$
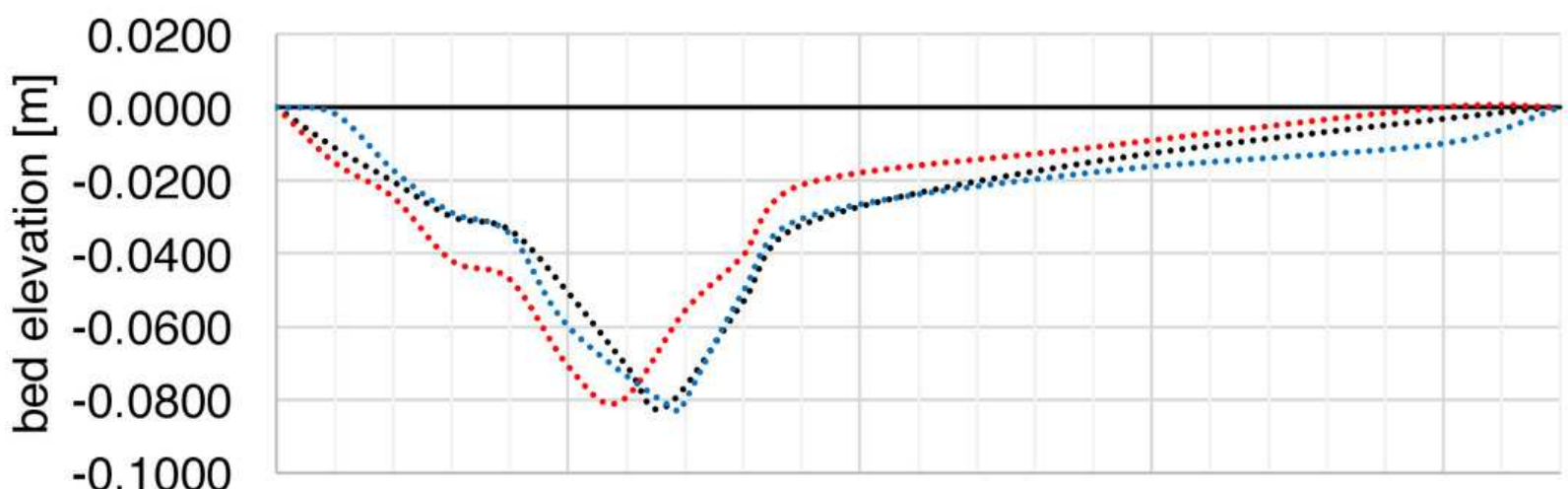

$\begin{array}{lllll}0.00 & 0.50 & 1.00 & 1.50 & 2.00\end{array}$

sandy bed length downstream the reinforcement [m]

c) $Q_{w}=0.026 \mathrm{~m}^{3} \mathrm{~s}^{-1} \quad h=0.10 \mathrm{~m} \quad q=0.0448 \mathrm{~m}^{3} \mathrm{~s}^{-1} \mathrm{~m}^{-1}$

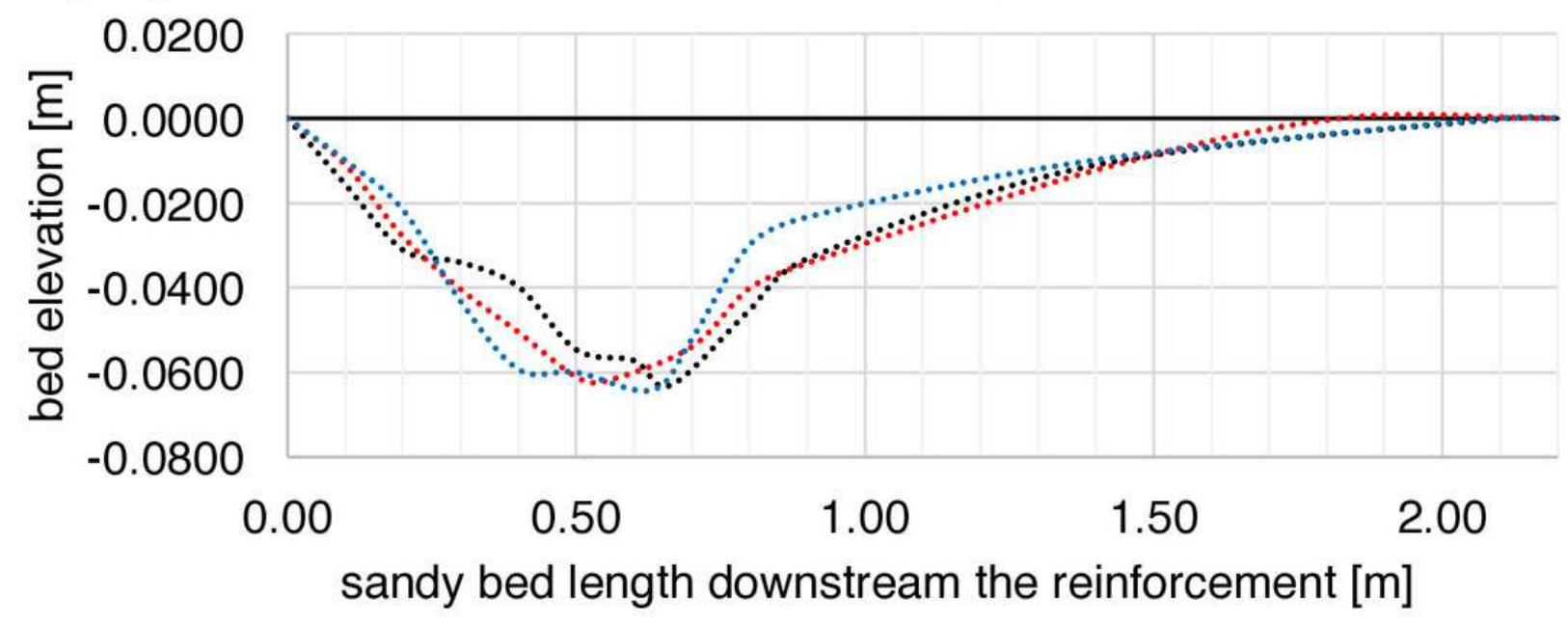


Figure 8

$k_{1}$ coefficient impact on the mean relative error of calculations using Rossinski formula (Eq. 1)

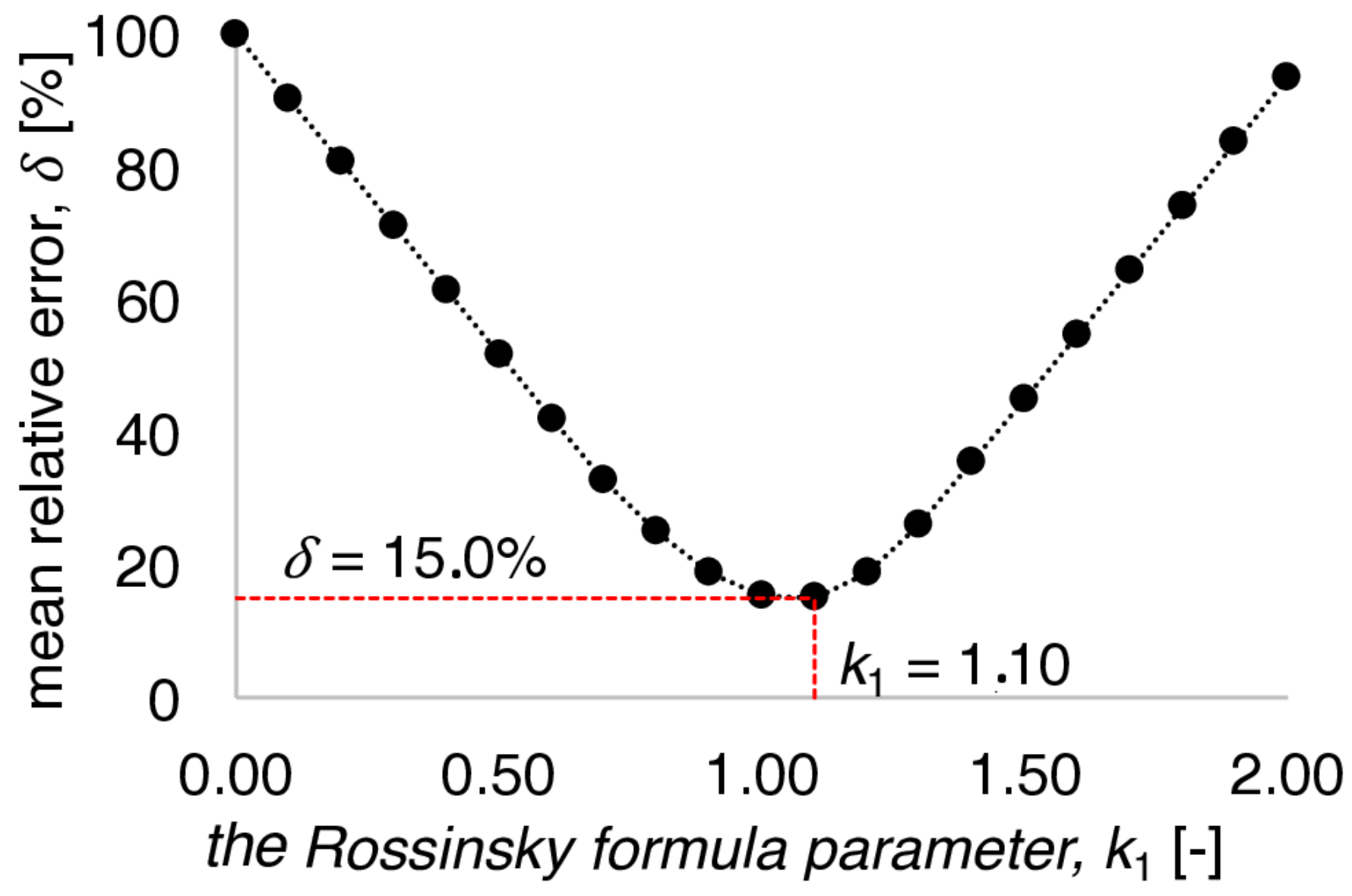


Figure 9

Local scour field characteristics

$z_{\max }$ - maximal scour depth; $\mathrm{h}$ - water depth before scour formation; $L_{s}$ - scour length

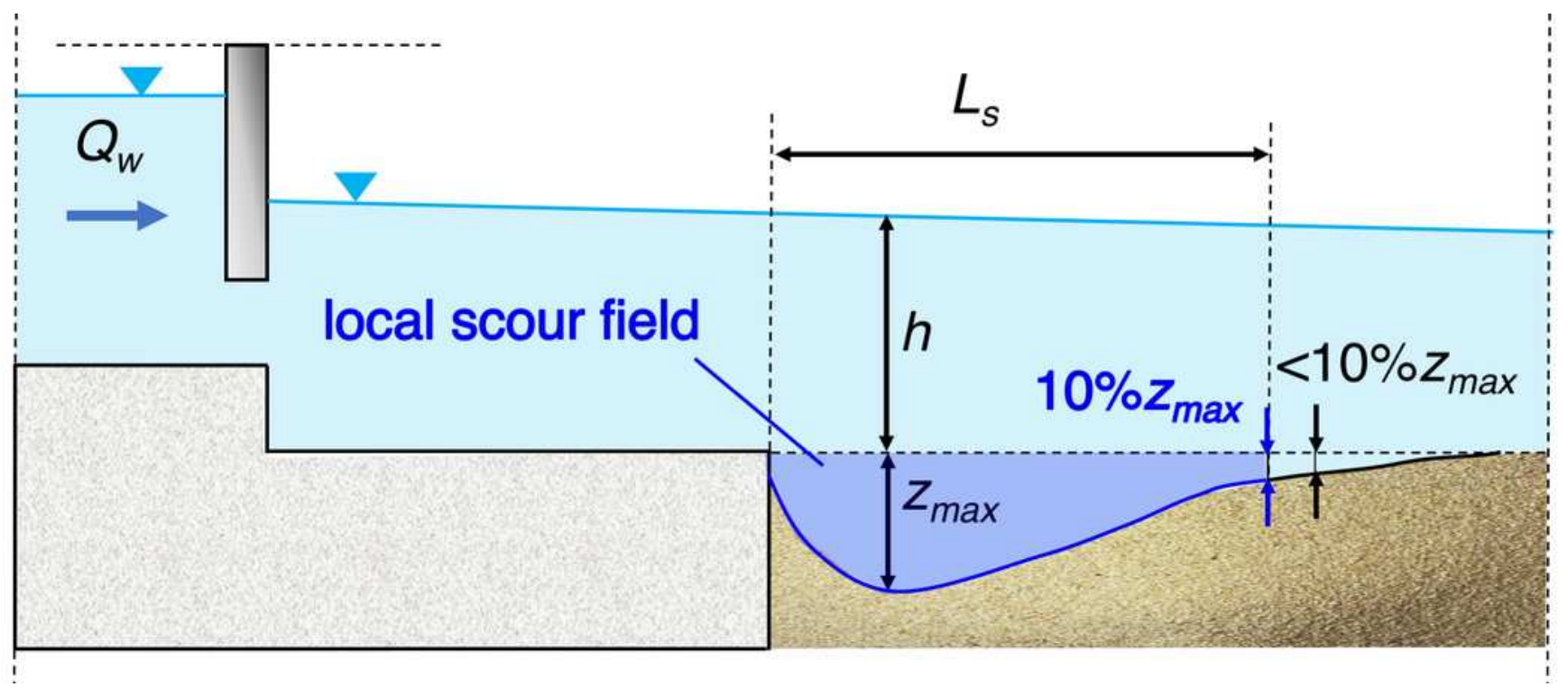


Figure 10

Local scour length $L_{s}$ measurements and calculations results.

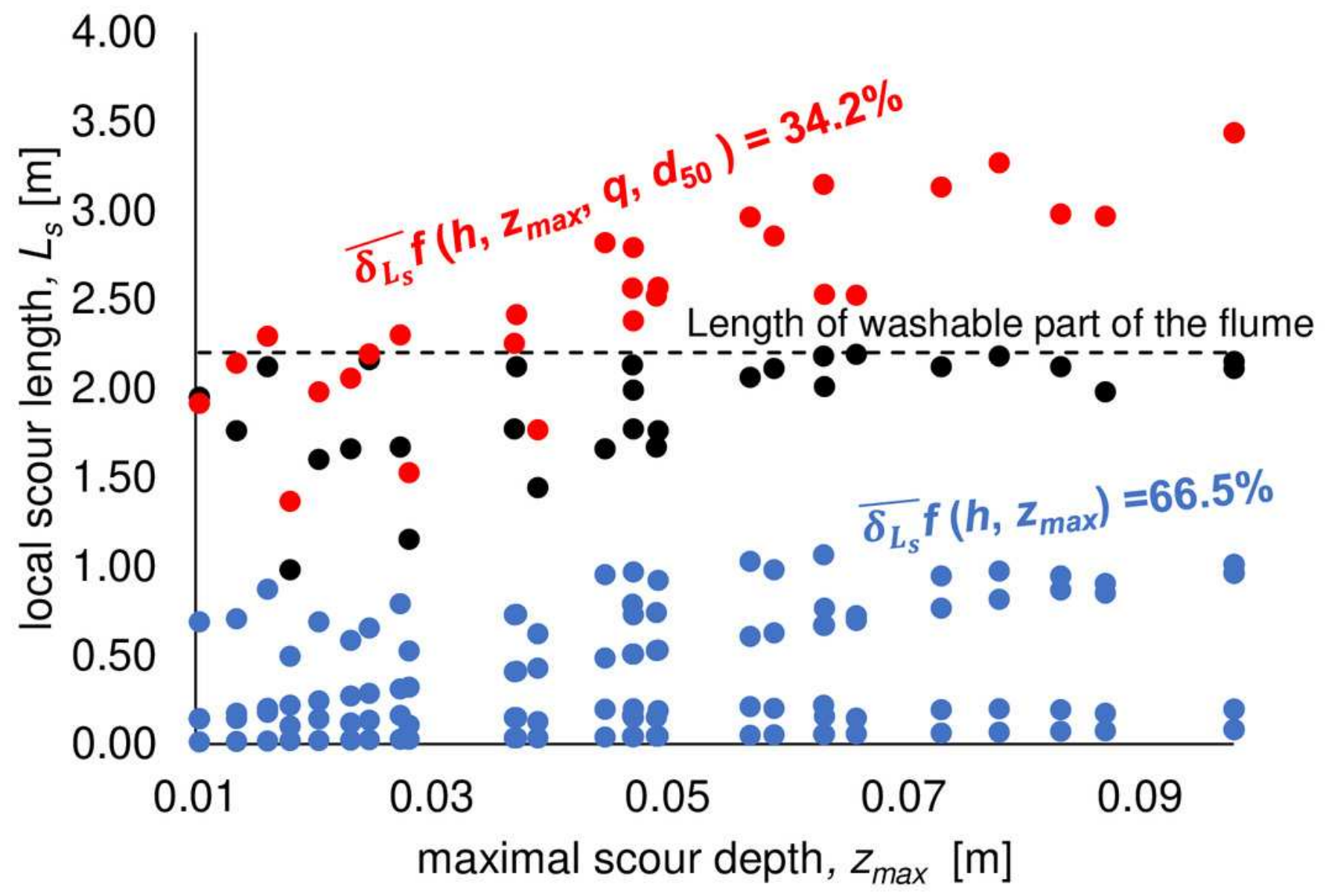


Figure 11

The distance between the deepest scour point and the end of reinforcement $L_{e}$ measurements and calculations results.

(a) - side view; (b) - the view from the upper stage of the weir (own elaboration after Urbański and Hejduk 2014).

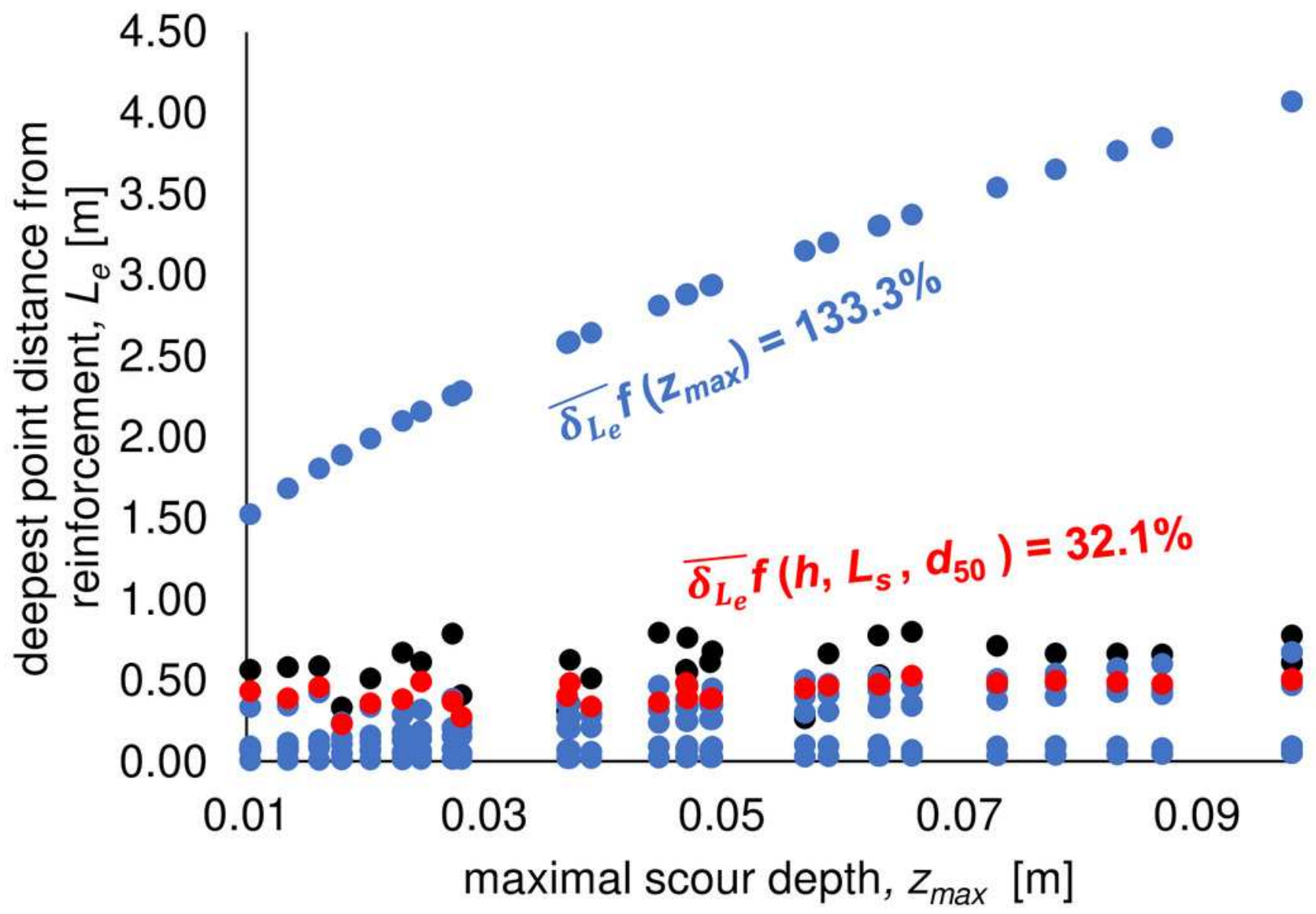


Figure 12

Weir in Czarna schematic

(a) - side view; (b) - the view from the upper stage of the weir (own elaboration after Urbański and Hejduk 2014).

a)

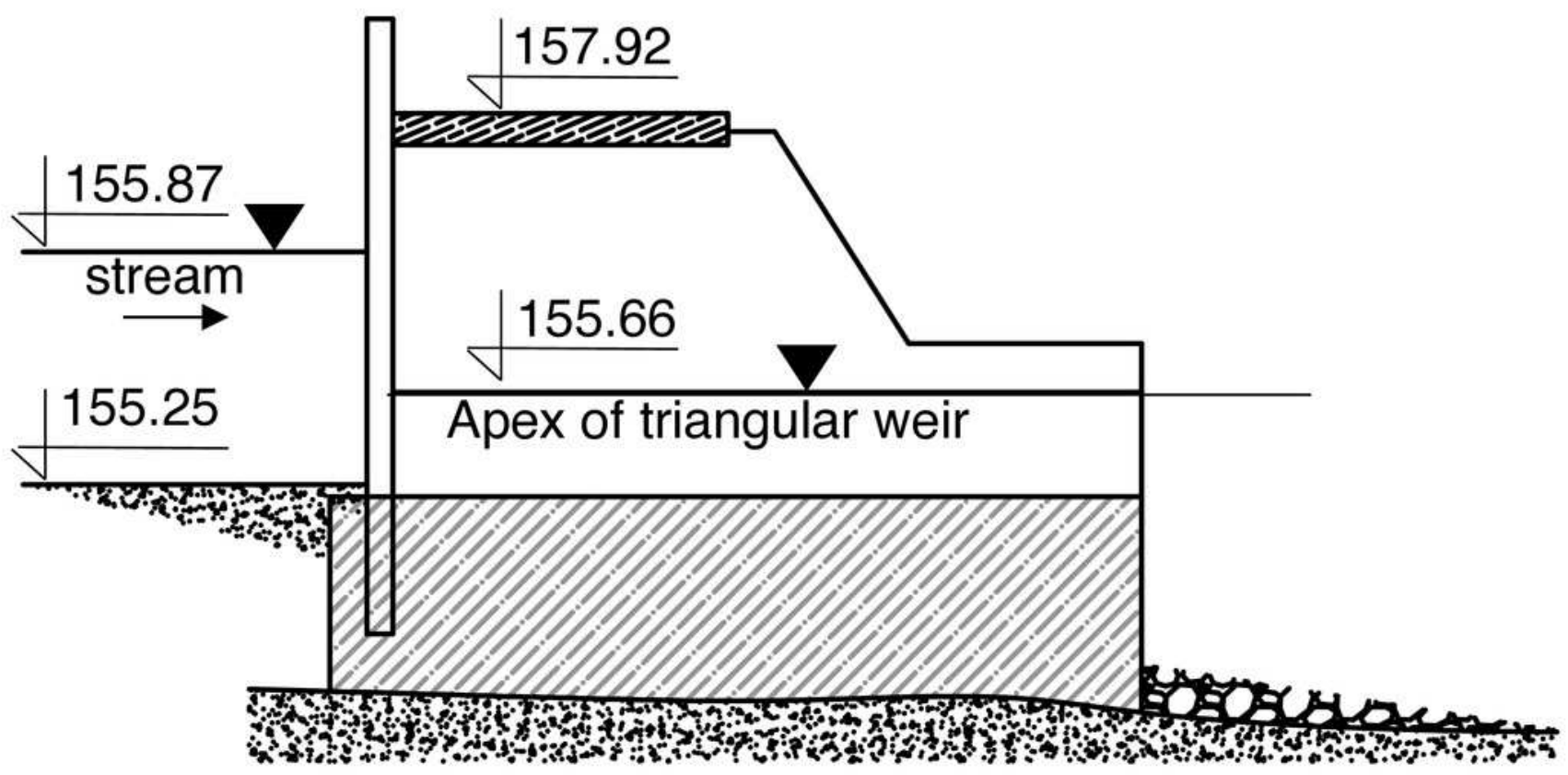

b)

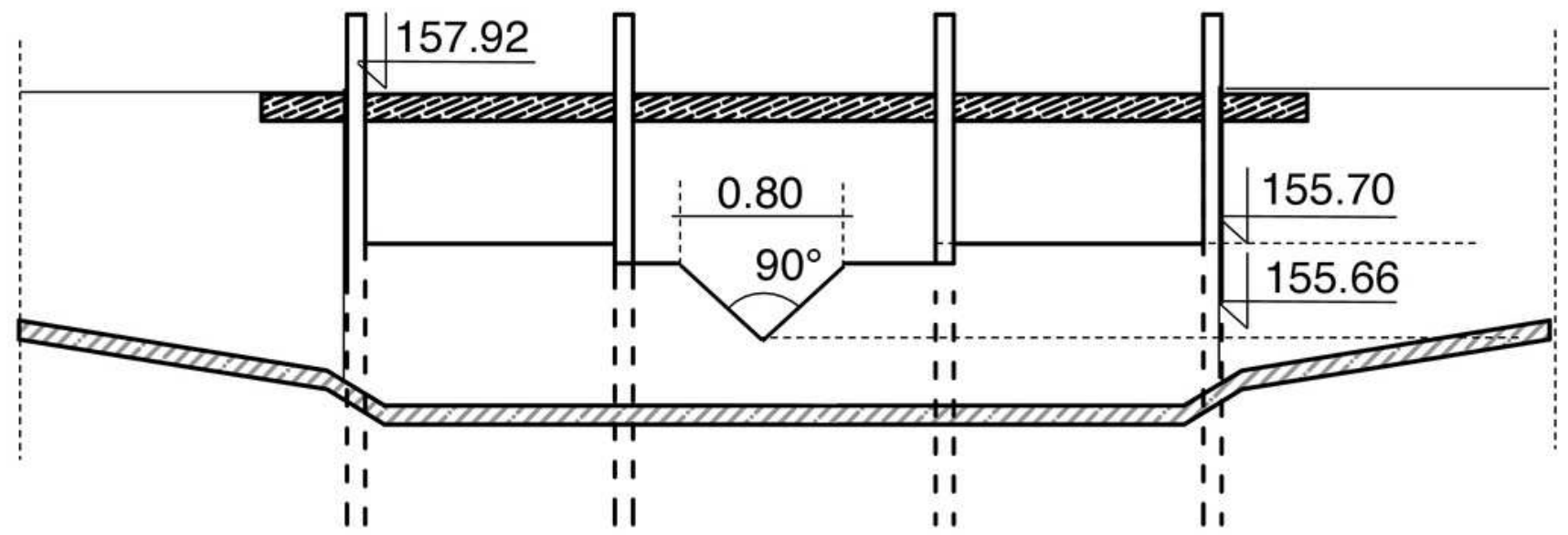




\section{Table $\mathbf{1}$ (on next page)}

Model I - measurement series summary table

Where: $Q_{w}$ - water flow discharge; $h$ - initial water depth in control profile; $T$ - measurement duration; $F r$ - Froude number. 
1

\begin{tabular}{|c|c|c|c|c|}
\hline $\begin{array}{c}\text { No of measurement } \\
\text { series }\end{array}$ & $\begin{array}{c}Q_{w} \\
{\left[\mathrm{~m}^{3} \cdot \mathrm{s}^{-1}\right]}\end{array}$ & $\begin{array}{c}h \\
{[\mathrm{~m}]}\end{array}$ & $\begin{array}{c}T \\
{[\mathrm{~s}]}\end{array}$ & $\begin{array}{c}F r \\
{[-]}\end{array}$ \\
\hline 1 & 0.025 & 0.13 & 28800 & 0.31 \\
\hline 2 & 0.020 & 0.05 & 28800 & 0.98 \\
\hline 3 & 0.023 & 0.10 & 28800 & 0.40 \\
\hline 4 & 0.030 & 0.08 & 28800 & 0.73 \\
\hline 5 & 0.025 & 0.05 & 28800 & 0.99 \\
\hline 6 & 0.030 & 0.11 & 28800 & 0.45 \\
\hline 7 & 0.028 & 0.11 & 28800 & 0.42 \\
\hline 8 & 0.026 & 0.10 & 28800 & 0.45 \\
\hline 9 & 0.029 & 0.08 & 28800 & 0.71 \\
\hline
\end{tabular}

2 


\section{Table 2 (on next page)}

Model II - measurement series summary table

Where: $Q_{w}$ - water flow discharge; $h$ - initial water depth in control profile; $T$ - measurement duration; $F r$ - Froude number. 
1

\begin{tabular}{|c|c|c|c|c|}
\hline $\begin{array}{c}\text { No of measurement } \\
\text { series }\end{array}$ & $\underset{\left[\mathrm{m}^{3} \cdot \mathrm{s}^{-1}\right]}{Q_{w}}$ & $\begin{array}{c}h \\
{[\mathrm{~m}]}\end{array}$ & $\begin{array}{c}T \\
{[\mathrm{~s}]}\end{array}$ & $\begin{array}{l}F r \\
{[-]}\end{array}$ \\
\hline 1 & 0.020 & 0.05 & 28800 & 0.98 \\
\hline 2 & 0.023 & 0.10 & 28800 & 0.40 \\
\hline 3 & 0.030 & 0.08 & 28800 & 0.73 \\
\hline 4 & 0.025 & 0.06 & 28800 & 0.99 \\
\hline 5 & 0.030 & 0.11 & 28800 & 0.45 \\
\hline 6 & 0.028 & 0.11 & 28800 & 0.42 \\
\hline 7 & 0.026 & 0.10 & 28800 & 0.45 \\
\hline 8 & 0.029 & 0.08 & 28800 & 0.71 \\
\hline 9 & 0.024 & 0.08 & 28800 & 0.58 \\
\hline 10 & 0.029 & 0.10 & 28800 & 0.50 \\
\hline 11 & 0.013 & 0.06 & 28800 & 0.48 \\
\hline 12 & 0.013 & 0.06 & 28800 & 0.57 \\
\hline 13 & 0.014 & 0.06 & 28800 & 0.52 \\
\hline 14 & 0.021 & 0.06 & 28800 & 0.78 \\
\hline 15 & 0.022 & 0.09 & 28800 & 0.46 \\
\hline 16 & 0.022 & 0.07 & 28800 & 0.65 \\
\hline 17 & 0.027 & 0.07 & 28800 & 0.80 \\
\hline 18 & 0.028 & 0.08 & 28800 & 0.67 \\
\hline 19 & 0.024 & 0.07 & 28800 & 0.72 \\
\hline 20 & 0.030 & 0.07 & 28800 & 0.88 \\
\hline
\end{tabular}

2 


\section{Table 3(on next page)}

Model I - scour geometry parameters summary table

Where: $q$ - unit water flow discharge; $z_{\max }$ - maximal scour depth; $L_{\mathrm{e}}$ - the distance between the deepest point of the hole and the end of reinforcement; $L_{s}$ - scour length. 
1

\begin{tabular}{|c|c|c|c|c|c|}
\hline $\begin{array}{c}\text { No of measurement } \\
\text { series }\end{array}$ & $\begin{array}{c}q \\
{\left[\mathrm{~m}^{3} \cdot \mathrm{s}^{-1} \cdot \mathrm{m}^{-1}\right]}\end{array}$ & $\begin{array}{c}z_{\max } \\
{[\mathrm{m}]}\end{array}$ & $\begin{array}{c}H_{\max } \\
{[\mathrm{m}]}\end{array}$ & $\begin{array}{c}L_{e} \\
{[\mathrm{~m}]}\end{array}$ & $\begin{array}{c}L_{s} \\
{[\mathrm{~m}]}\end{array}$ \\
\hline 1 & 0.0431 & 0.0201 & 0.1451 & 0.59 & 2.10 \\
\hline 2 & 0.0345 & 0.0911 & 0.1411 & 0.66 & 2.10 \\
\hline 3 & 0.0397 & 0.0532 & 0.1532 & 0.68 & 2.20 \\
\hline 4 & 0.0517 & 0.0821 & 0.1621 & 0.67 & 2.18 \\
\hline 5 & 0.0431 & 0.1020 & 0.1600 & 0.78 & 2.01 \\
\hline 6 & 0.0517 & 0.0672 & 0.1772 & 0.78 & 2.18 \\
\hline 7 & 0.0483 & 0.0511 & 0.1611 & 0.76 & 2.20 \\
\hline 8 & 0.0448 & 0.0630 & 0.1630 & 0.66 & 2.20 \\
\hline 9 & 0.0500 & 0.0772 & 0.1572 & 0.71 & 2.20 \\
\hline
\end{tabular}

2 


\section{Table 4(on next page)}

Model II - scour geometry parameters summary table

Where: $q$ - unit water flow discharge; $z_{\max }$ - maximal scour depth; $L_{\mathrm{e}}$ - the distance between the deepest point of the hole and the end of reinforcement; $L_{s}$ - scour length. 


\begin{tabular}{|c|c|c|c|c|c|}
\hline $\begin{array}{c}\text { No of measurement } \\
\text { series }\end{array}$ & $\begin{array}{c}q \\
{\left[\mathrm{~m}^{3} \cdot \mathrm{s}^{-1} \cdot \mathrm{m}^{-1}\right]}\end{array}$ & $\begin{array}{c}z_{\max } \\
{[\mathrm{m}]}\end{array}$ & $H_{\max }[\mathrm{m}]$ & $\begin{array}{c}L_{e} \\
{[\mathrm{~m}]}\end{array}$ & $\begin{array}{c}L_{s} \\
{[\mathrm{~m}]}\end{array}$ \\
\hline 1 & 0.0345 & 0.0700 & 0.1200 & 0.80 & 2.19 \\
\hline 2 & 0.0397 & 0.0143 & 0.1143 & 0.56 & 2.20 \\
\hline 3 & 0.0517 & 0.0287 & 0.1087 & 0.61 & 2.20 \\
\hline 4 & 0.0431 & 0.1020 & 0.1600 & 0.61 & 2.20 \\
\hline 5 & 0.0517 & 0.0487 & 0.1587 & 0.79 & 2.20 \\
\hline 6 & 0.0483 & 0.0610 & 0.1710 & 0.27 & 2.20 \\
\hline 7 & 0.0448 & 0.0313 & 0.1313 & 0.79 & 2.20 \\
\hline 8 & 0.0500 & 0.0412 & 0.1212 & 0.63 & 2.20 \\
\hline 9 & 0.0414 & 0.0410 & 0.1210 & 0.31 & 1.77 \\
\hline 10 & 0.0500 & 0.0175 & 0.1175 & 0.58 & 2.20 \\
\hline 11 & 0.0220 & 0.0220 & 0.0820 & 0.33 & 1.00 \\
\hline 12 & 0.0231 & 0.0321 & 0.0871 & 0.41 & 1.10 \\
\hline 13 & 0.0240 & 0.0430 & 0.1030 & 0.51 & 1.50 \\
\hline 14 & 0.0360 & 0.0673 & 0.1273 & 0.53 & 1.98 \\
\hline 15 & 0.0385 & 0.0244 & 0.1144 & 0.51 & 1.60 \\
\hline 16 & 0.0375 & 0.0873 & 0.1573 & 0.66 & 2.20 \\
\hline 17 & 0.0465 & 0.0530 & 0.1230 & 0.61 & 2.20 \\
\hline 18 & 0.0475 & 0.0510 & 0.1310 & 0.56 & 2.13 \\
\hline 19 & 0.0415 & 0.0511 & 0.1211 & 0.55 & 2.01 \\
\hline 20 & 0.0510 & 0.0271 & 0.0971 & 0.67 & 1.70 \\
\hline
\end{tabular}

1

2 


\section{Table 5 (on next page)}

Formulas verification summary table

Where: (1 - 17) - number of formula; $d_{\text {Hmax }}$ - an error of the depth of the water above the deepest point of the scour calculation; ; $d_{L s}$ - an error of the scour length calculation; $d_{L e}$ - an error of the distance between the deepest point of the scour and the end of reinforcement calculation. 


\begin{tabular}{|c|c|c|c|}
\hline Author's Name & $d_{H \max }[\%]$ & $d_{L s}[\%]$ & $d_{L e}[\%]$ \\
\hline Rossinski & $(1) 15.0 \%$ & & \\
\hline Shalash \& Franke & & $(4) 69.8 \%$ & $(5) 45.2 \%$ \\
\hline Müller & & $(7) 72.8 \%$ & $(8) 57.0 \%$ \\
\hline Müller & & $(10) 56.9 \%$ & $(11) 38.3 \%$ \\
\hline Straube & & $(13) 34.2 \%$ & $(15) 32.1 \%$ \\
\hline $\begin{array}{c}\text { (Optimized) } \\
\text { Straube }\end{array}$ & & $(20) 10.1 \%$ & $(21) 18.2 \%$ \\
\hline Tajarmovič & & & $(17) 392.7 \%$ \\
\hline
\end{tabular}




\section{Table 6(on next page)}

Hydraulic flow parameters and local scour properties in Gaudio \& Marion (2010) model experiments with Straube formula verification

Where: $q$ - unit water flow discharge; $h$ - water depth before scour formation; $z_{\max }$ - maximal scour depth; $L_{s}$ - total scour length; $\delta$ - relative error. 


\begin{tabular}{|c|c|c|c|c|c|c|c|c|}
\hline $\begin{array}{c}\text { No of } \\
\text { test }\end{array}$ & $q$ & $h$ & $z_{\max }$ & $L_{s}$ & $\begin{array}{c}\text { Straube } \\
\text { original } \\
\text { (Eq. 13) } \\
L_{s}\end{array}$ & $\begin{array}{c}\text { Straube } \\
\text { optimized } \\
\text { Eq. 20) } \\
L_{s}\end{array}$ & $\begin{array}{c}\text { Straube } \\
\text { original } \\
\text { (Eq. 13) } \\
\text { relative } \\
\text { error } \\
\delta\end{array}$ & $\begin{array}{c}\text { Straube } \\
\text { optimized } \\
\text { (Eq. 20) } \\
\text { relative } \\
\text { error } \\
\delta\end{array}$ \\
\hline- & $\mathrm{m}^{2} \cdot \mathrm{s}^{-1}$ & {$[\mathrm{~m}]$} & {$[\mathrm{m}]$} & {$[\mathrm{m}]$} & {$[\mathrm{m}]$} & {$[\mathrm{m}]$} & {$[\%]$} & {$[\%]$} \\
\hline 1 & 0.020 & 0.050 & 0.084 & 1.25 & 2.10 & 1.63 & $68.4 \%$ & $30.1 \%$ \\
\hline 2 & 0.032 & 0.065 & 0.097 & 1.65 & 2.71 & 2.09 & $64.5 \%$ & $26.6 \%$ \\
\hline 3 & 0.021 & 0.050 & 0.071 & 1.35 & 1.93 & 1.50 & $43.3 \%$ & $10.8 \%$ \\
\hline 4 & 0.025 & 0.062 & 0.068 & 1.47 & 2.03 & 1.56 & $38.1 \%$ & $6.1 \%$ \\
\hline 5 & 0.021 & 0.050 & 0.058 & 1.43 & 1.73 & 1.34 & $20.7 \%$ & $6.6 \%$ \\
\hline 6 & 0.028 & 0.071 & 0.083 & 1.25 & 2.37 & 1.81 & $89.9 \%$ & $45.1 \%$ \\
\hline 7 & 0.030 & 0.070 & 0.095 & 1.90 & 2.62 & 2.01 & $38.0 \%$ & $5.7 \%$ \\
\hline 8 & 0.021 & 0.050 & 0.087 & 1.50 & 2.19 & 1.69 & $46.0 \%$ & $12.9 \%$ \\
\hline 9 & 0.024 & 0.060 & 0.102 & 1.55 & 2.53 & 1.94 & $63.0 \%$ & $25.3 \%$ \\
\hline 10 & 0.030 & 0.070 & 0.110 & 1.63 & 2.86 & 2.19 & $75.5 \%$ & $34.4 \%$ \\
\hline 11 & 0.027 & 0.065 & 0.084 & 1.98 & 2.35 & 1.80 & $18.6 \%$ & $9.0 \%$ \\
\hline 12 & 0.020 & 0.060 & 0.069 & 1.52 & 1.88 & 1.44 & $23.9 \%$ & $5.1 \%$ \\
\hline & & & & & Mean relative error & $49.2 \%$ & $18.1 \%$ \\
\hline
\end{tabular}

1

2

3

4 


\section{Table 7 (on next page)}

Field measurements and calculations results summary table - Czarna Gauge

$z_{\text {max }}$ - maximal scour depth; $h$ - water depth before scour formation; $L_{s}$ - scour length; $L_{e}$ - the distance between the deepest point of the hole and the end of reinforcement. 
1

\begin{tabular}{|c|c|c|c|}
\hline & \multicolumn{3}{|c|}{ Geometric scour parameters } \\
\hline & $H_{\max }=z_{\max }+h[\mathrm{~m}]$ & $L_{s}[\mathrm{~m}]$ & $L_{e}[\mathrm{~m}]$ \\
\hline Field measurements & 2.43 & 13.8 & 5.2 \\
\hline Author: & Calculations results using Eqs. (1), (7)-(21) (error \%) \\
\hline Rossinski & $(1) 3.39$ & & \\
\hline Müller & $(39.5 \%)$ & & $\mathbf{( 8 )} \mathbf{5 . 0 - 6 . 1}$ \\
& & $(7) 10.3-12.1$ & $\mathbf{( 0 \% )}$ \\
\hline Müller & & $\mathbf{( 1 0 )} \mathbf{1 1 . 6}-\mathbf{1 7 . 5}$ & $\mathbf{( 1 1 ) 5 . 7 - 8 . 6}$ \\
& & $\mathbf{( 0 \% )}$ & $(9.6 \%)$ \\
\hline Straube & & $(13) 21.7$ & $(15) 4.8$ \\
& & $(57.2 \%)$ & $(7.7 \%)$ \\
\hline (Optimized) Straube & & $\mathbf{( 2 0 )} \mathbf{1 3 . 8}$ & $(21) 4.3$ \\
& & $\mathbf{( 0 . 2 \% )}$ & $(16.6 \%)$ \\
\hline Tajarmovič & & & $(17) 4.8$ \\
& & & $(159.6 \%)$ \\
\hline
\end{tabular}

2

3 